\title{
Future Projections of East Asian Climate Change from Multi-AOGCM Ensembles of IPCC SRES Scenario Simulations
}

\author{
Seung-Ki MIN \\ Meteorologisches Institut, Universität Bonn, Bonn, Germany \\ E-Hyung PARK and Won-Tae KWON \\ Meteorological Research Institute, Korea Meteorological Administration, Seoul, Korea \\ (Manuscript received 26 August 2003, in final form 26 April 2004)
}

\begin{abstract}
In this paper, future climate changes over East Asia $\left(20-50^{\circ} \mathrm{N}, 100-145^{\circ} \mathrm{E}\right)$ are projected from multimodel ensembles (MMEs) of selected coupled atmosphere-ocean general circulation model (AOGCM) simulations based on Intergovernmental Panel on Climate Change (IPCC) Special Report on Emissions Scenarios (SRES) A2 and B2 scenarios. Analyzed variables include annual and seasonal near surface temperature and precipitation over East Asia. Before projecting future climate, model performances are evaluated on the simulation of the present-day climate (1961-1990) with bias, root-mean squared error (RMSE), and the Taylor diagram analysis. The result of model evaluation shows that CSIRO Mk2, ECHAM4/OPYC3, GFDL_R30_c, and HadCM3 exhibit higher performance. In order to test the sensitivity of projection results, four MMEs are defined: simple arithmetic averages of all seven AOGCM simulations (MME7) and four skillful AOGCM simulations (MME4), and skill-weighted averages of seven AOGCM simulations based on the skill scores of the Taylor diagram (MME_S1 and MME_S2). While the weighted MMEs (MME_S1 and MME_S2) have similar performances in the present-day climate simulation to that of MME7, MME4 constructed by four skillful models reveals higher performance than the other MMEs.

The overall projection results from four MMEs show that East Asia will experience warmer and wetter climate in the 21 st century. The projection results are not sensitive to the MME method. Areaaveraged temperature changes for three 30-year periods of 2020s, 2050s, and 2080s simulated by MME7 $\mathrm{A} 2$ [B2] scenario ensembles are 1.2 [1.4], 2.5 [2.4], and $4.1^{\circ} \mathrm{C}$ [3.2 ${ }^{\circ} \mathrm{C}$ ] increase, and precipitation changes are 0.4 [1.4], 2.2 [2.6], and 5.0\% [4.0\%] increase, respectively. Spatial patterns indicate that both temperature and precipitation increases are larger over the continental area than the oceanic area, and that the areas of larger inter-model variability are in accord with those of stronger climate change. The intermodel variability (noise) in precipitation changes is as large as that of ensemble mean (signal), whereas noise is much smaller than signal in the projection of temperature changes. It is demonstrated that MME4 reduces the inter-model uncertainty about a half of MME7 in the temperature projection of the late 21st century, but not in the precipitation projection. A significant difference in projected patterns between A2 and B2 scenario ensembles (defined as a potential impact of greenhouse-gas mitigation) appears in the 2080s temperature field over the southwestern part of East Asia. However, no significant differences can be found between precipitation patterns of A2 and B2 scenario ensembles because of the
\end{abstract}

Corresponding author: Seung-Ki Min, Meteor-

ologisches Institut, Universität Bonn, Auf dem

Hügel 20, 53121 Bonn, Germany.

E-mail: skmin@uni-bonn.de

(C) 2004, Meteorological Society of Japan 
dominant inter-model variability. It is also shown that the climate change over East Asia has a characteristic seasonal dependence, that is, larger increases of wintertime temperature and summertime precipitation, which implicates the possible change of the East Asian monsoon system by global warming.

\section{Introduction}

Multi-model ensemble (MME) is defined as average of simulation results from multiple models. MME is used to reduce the effects of uncertainty originating from different initial conditions and characteristic biases of individual models. MME method has been applied to seasonal predictions from atmospheric general circulation models (AGCMs) (Krishnamurti et al. 2000; Kharin and Zwiers 2002; Yun et al. 2003; Yun and Kwon 2003), model evaluation or estimation of the climatology from coupled atmosphere-ocean GCMs (AOGCMs) (McAvaney et al. 2001), climate change projection from AOGCMs (Cubasch et al. 2001; Giorgi and Mearns 2002; Lal and Harasawa 2001), and climate change detection from AOGCMs (Gillett et al. 2002).

The AOGCMs have been used for projections of future climate change with spatial scales of hundreds of kilometers and larger. MMEs of AOGCM simulations were assessed by the Intergovernmental Panel on Climate Change (IPCC) for the period of 1990 to 2100 based on a range of emissions scenarios for greenhouse gases (GHGs) and sulfate aerosols. Total ten and eight AOGCMs were used for IPCC IS92a (Pepper et al. 1992) and the Special Report on Emissions Scenarios (SRES) (Nakicenovic and Swart 2000), respectively (data available from IPCC Data Distribution Center (DDC) at http:// ipcc-ddc.cru.uea.ac.uk). For climate change detection and attribution problem, control simulations of AOGCMs are used to estimate internal variability (noise) of climate system and forced simulations of AOGCMs provide fingerprints (signal) of climate change (Mitchell et al. 2001).

Giorgi and Mearns (2002) introduced a kind of weighted MME, referred to as the Reliability Ensemble Average (REA), using the bias of the present climate simulation and the difference from ensemble mean in the future climate for the 22 continental regions. Lal and Harasawa (2001) projected climate change over the Asian continent from four skillful AOGCM simula- tions based on the IPCC IS92a scenario selected by analyzing spatial pattern correlations and root-mean squared errors (RMSEs).

In this study, the projection results of the previous works focusing on the East Asian region are updated using seven AOGCM simulations based on the SRES A2 and B2 scenarios. More comprehensive method of model evaluation is introduced to construct MMEs with skillful AOGCMs and the affect of skillful models on the noise level in the projection result is assessed. Assuming that we can reduce GHG emissions by the level of the B2 scenario from that of the A2 scenario, a potential impact of GHG mitigation is estimated by comparing the MME results of the A2 and B2 scenarios. In addition, monthly and seasonal climate change is examined to see whether the annual cycle of temperature and precipitation over East Asia will be changed in the future.

Data and methodology are described in the next section. MME constructions from seven AOGCMs are explained along with model evaluation on their present-day climate simulations in section 3. Future projections of temperature and precipitation over East Asia are provided in section 4 with emphasis on inter-model uncertainty, a potential impact of GHG mitigation, and seasonal dependence of climate change. Conclusions are given with some discussions in the final section.

\section{Data and methodology}

The East Asian region is defined as the domain of $20-50^{\circ} \mathrm{N}$ and $100-145^{\circ} \mathrm{E}$, which is the same as in Giorgi and Mearns (2002) and Lal and Harasawa $(2000,2001)$. Analysis variables include monthly to annual mean near surface temperature and precipitation. Table 1 summarizes the experiments of SRES A2 and B2 scenario simulations with seven AOGCMs with descriptions of atmospheric and oceanic resolutions, flux adjustments, cumulus convection schemes, aerosol forcing effects, and key references. Among seven AOGCMs, HadCM3, and DOE PCM do not use flux adjustments, and ECHAM4/OPYC3 has a distinct flux correction 
Table 1. AOGCM experiments based on the IPCC SRES A2 and B2 scenarios used in this study.

\begin{tabular}{|c|c|c|c|c|c|c|c|}
\hline $\begin{array}{l}\text { Model name } \\
\text { Center }^{\mathrm{a}}\end{array}$ & $\begin{array}{l}\text { Starting } \\
\text { and } \\
\text { ending } \\
\text { year }\end{array}$ & $\begin{array}{l}\text { Atmospheric } \\
\text { resolution }^{b}\end{array}$ & $\begin{array}{c}\text { Oceanic } \\
\text { resolution }^{\mathrm{c}}\end{array}$ & $\begin{array}{c}\text { Flux } \\
\text { adjustment }^{\mathrm{d}}\end{array}$ & $\begin{array}{l}\text { Cumulus } \\
\text { convection } \\
\text { scheme }\end{array}$ & $\begin{array}{c}\text { Aerosol } \\
\text { forcing } \\
\text { effect }^{f}\end{array}$ & References \\
\hline $\begin{array}{l}\text { CGCM2 } \\
\text { CCCma }\end{array}$ & $\begin{array}{c}1900- \\
2100\end{array}$ & $\begin{array}{c}\text { T32 } \\
(3.8 \times 3.8) \\
\text { L10 }\end{array}$ & $\begin{array}{c}1.875 \times 1.875 \\
\text { L29 }\end{array}$ & $\mathrm{H}, \mathrm{W}$ & $\begin{array}{l}\text { Moist convective } \\
\text { adjustment } \\
\text { similar to } \\
\text { Manabe } \\
\text { et al. (1965) }\end{array}$ & $\mathrm{D}$ & $\begin{array}{c}\text { Flato and } \\
\text { Boer } \\
(2001)\end{array}$ \\
\hline $\begin{array}{l}\text { CCSR/NIES2 } \\
C C S R \text { / NIES }\end{array}$ & $\begin{array}{c}1890- \\
2100\end{array}$ & $\begin{array}{c}\mathrm{T} 21 \\
(5.6 \times 5.6) \\
\mathrm{L} 20\end{array}$ & $\begin{array}{l}2.8 \times 2.8 \\
\quad \text { L17 }\end{array}$ & $\mathrm{H}, \mathrm{W}$ & $\begin{array}{c}\text { Relaxed } \\
\text { Arakawa- } \\
\text { Schubert } \\
\text { (Moorthi and } \\
\text { Suarez 1992) }\end{array}$ & $\begin{array}{l}\mathrm{D}, \mathrm{I} 1 \\
\quad \mathrm{I} 2\end{array}$ & $\begin{array}{c}\text { Nozawa } \\
\text { et al. } \\
(2001)\end{array}$ \\
\hline $\begin{array}{l}\text { CSIRO Mk2 } \\
\text { CSIRO }\end{array}$ & $\begin{array}{c}1961- \\
2100\end{array}$ & $\begin{array}{c}\mathrm{R} 21 \\
(3.25 \times 5.625) \\
\mathrm{L} 9\end{array}$ & $\begin{array}{c}3.25 \times 5.625 \\
\mathrm{~L} 21\end{array}$ & $\mathrm{H}, \mathrm{W}, \mathrm{M}$ & $\begin{array}{l}\text { Modified } \\
\text { Arakawa } \\
\text { "soft" moist } \\
\text { convective } \\
\text { adjustment } \\
\text { (Arakawa } \\
\text { 1972) and mass } \\
\text { flux scheme }\end{array}$ & $\mathrm{D}$ & $\begin{array}{l}\text { Gordon } \\
\text { and } \\
\text { O'Farrell } \\
(1997)\end{array}$ \\
\hline $\begin{array}{c}\text { ECHAM4/ } \\
\text { OPYC3 } \\
\text { MPIfM }\end{array}$ & $\begin{array}{c}1990- \\
2100\end{array}$ & $\begin{array}{c}\mathrm{T} 42 \\
(2.8 \times 2.8) \\
\mathrm{L} 19\end{array}$ & $\begin{array}{c}2.8 \times 2.8^{\#} \\
\text { L11 }\end{array}$ & $\mathrm{H}^{*}, \mathrm{~W}^{*}$ & $\begin{array}{l}\text { Mass flux scheme } \\
\text { (Tiedtke 1989) } \\
\text { with an } \\
\text { adjustment } \\
\text { closure based } \\
\text { on CAPE } \\
\text { (Nordeng 1994) }\end{array}$ & $\mathrm{D}, \mathrm{I} 1$ & $\begin{array}{l}\text { Stendel } \\
\text { et al. } \\
(2002)\end{array}$ \\
\hline $\begin{array}{c}\text { GFDL_R30_c } \\
G F D L\end{array}$ & $\begin{array}{l}1965- \\
2104\end{array}$ & $\begin{array}{c}\text { R30 } \\
(2.25 \times 3.75) \\
\mathrm{L} 14\end{array}$ & $\begin{array}{c}2.25 \times 1.875 \\
\mathrm{~L} 18\end{array}$ & $\mathrm{H}, \mathrm{W}$ & $\begin{array}{l}\text { Moist convective } \\
\text { adjustment } \\
\text { (Manabe et } \\
\text { al. 1965) }\end{array}$ & $\mathrm{D}$ & $\begin{array}{l}\text { Delworth } \\
\text { et al. } \\
(2002)\end{array}$ \\
\hline $\begin{array}{c}\text { HadCM3 } \\
H C C P R\end{array}$ & $\begin{array}{c}1950- \\
2099\end{array}$ & $\begin{array}{c}2.5 \times 3.75 \\
\text { L19 }\end{array}$ & $\begin{array}{c}1.25 \times 1.25 \\
\mathrm{~L} 20\end{array}$ & - & $\begin{array}{c}\text { Mass flux } \\
\text { penetrative } \\
\text { convective scheme } \\
\text { (Gregory and } \\
\text { Rowntree 1990) } \\
\text { and modification } \\
\text { (Gregory et al. } \\
\text { 1997) }\end{array}$ & $\mathrm{D}, \mathrm{I} 1$ & $\begin{array}{l}\text { Johns } \\
\text { et al. } \\
\text { (2003) }\end{array}$ \\
\hline $\begin{array}{c}\text { DOE PCM } \\
N C A R\end{array}$ & \begin{tabular}{|c} 
A2: $1981-$ \\
2099 \\
B2: $2001-$ \\
2099
\end{tabular} & $\begin{array}{c}\mathrm{T} 42 \\
(2.8 \times 2.8) \\
\mathrm{L} 18\end{array}$ & $\begin{array}{c}0.67 \times 0.67^{\#} \\
\text { L32 }\end{array}$ & - & $\begin{array}{c}\text { Simplified } \\
\text { Arakawa- } \\
\text { Schubert (Zhang } \\
\text { and McFarlane } \\
\text { 1995) }\end{array}$ & $\mathrm{D}$ & $\begin{array}{l}\text { Washington } \\
\text { et al. } \\
\text { (2000) } \\
\text { Dai et al. } \\
\text { (2001) }\end{array}$ \\
\hline
\end{tabular}

a. Canadian Center for Climate Modelling and Analysis (CCCma), Center for Climate Research Studies (CCSR)/National Institute for Environmental Studies (NIES), Commonwealth Scientific and Industrial Research Organization (CSIRO), Max-Planck-Institute für Meteorologie (MPIfM), Geophysical Fluid Dynamics Laboratory (GFDL), Hadley Centre for Climate Prediction and Research (HCCPR), and National Center for Atmospheric Research (NCAR). 
Table 1. (Continued)

b. Atmospheric and oceanic resolutions are expressed as latitude $\left(^{\circ}\right) \times$ longitude $\left(^{\circ}\right)$ with spectral truncations and ' $L$ ' + number of vertical levels.

c. A sharp (\#) depicts the use of equatorial refinement.

d. $\mathrm{H}=$ heat flux; $\mathrm{W}=$ freshwater flux, $\mathrm{M}=$ momentum flux. An asterisk (*) indicates annual mean flux adjustment only.

e. Convective available potential energy (CAPE).

f. D: direct radiative cooling effect of the aerosols, I1: first indirect effect of the aerosols (cloud albedo effect), and I2: second indirect effect of the aerosols (cloud lifetime effect).

of annual mean values rather than monthly means. All model simulation data are interpolated into the same $5^{\circ} \times 5^{\circ}$ grids as the observations before analysis. We construct and use mainly two MMEs; one is the average of all seven AOGCMs, which is referred to as MME7, and the other is MME4 defined from four selected AOGCMs of higher performance. To select skillful AOGCMs their present-day climate is validated with bias, RMSE, spatial pattern correlation, and standard deviation. The pattern correlation and standard deviation is evaluated with the help of the Taylor diagram (Taylor 2001). Table 2 enlists the experiments of present-day climate simulations from three AOGCMs, A2 and B2 simulations of which exclude the present-day period (see Table 1).

After bias and RMSE are first analyzed to validate uncentered statistics in individual models, the Taylor diagram analysis is applied to evaluate centered statistics (pattern correlation and spatial variance). The Taylor diagram displays three pattern statistics on a 2-D plot (McAvaney et al. 2001; Taylor 2001): ratio of the variances of the two fields $\left(\tilde{\sigma}_{f}\right)$, correlation between two fields $(R)$, and centered root mean squared difference between two fields $\left(\tilde{\boldsymbol{E}}^{\prime}\right)$. The Taylor diagram provides simple and easily interpretable results of model evaluation or inter-comparison and can be used to a number of applications (Taylor 2001). However, it has a shortcoming that it does not consider un- centered statistics. Boer and Lambert (2001) suggested an alternative diagram to overcome the shortcoming in the Taylor diagram, but their diagram has disadvantages as using the "effective" correlation coefficient, which is defined as a weighted difference between two true correlation coefficients, so more difficult to interpret (Taylor 2001).

In order to evaluate quantitatively the model performance from the Taylor diagram, we use two skill scores $S_{1}$ and $S_{2}$ devised by Taylor (2001), although they were offered as illustrative examples to guide in developing better skill scores (Taylor 2001):

$$
\begin{aligned}
& S_{1}=\frac{4(1+R)}{\left(\tilde{\sigma}_{f}+1 / \tilde{\sigma}_{f}\right)^{2}\left(1+R_{0}\right)}, \\
& S_{2}=\frac{4(1+R)^{4}}{\left(\tilde{\sigma}_{f}+1 / \tilde{\sigma}_{f}\right)^{2}\left(1+R_{0}\right)^{4}},
\end{aligned}
$$

where $R_{0}$ is the maximum correlation attainable. As the model variance approaches the observed variance and the pattern correlation between model and observation approaches to $R_{0}$, the scores approach unity. As the variance ratio approaches zero or infinite or as the correlation gets close to negative unity, skills approach zero. The score $S_{1}$ places emphasis on variance performance while pattern correlation between model and observation is more importantly treated in the score $S_{2}$. Using the scores $S_{1}$ and $S_{2}$ as weighting factors in calculating model

Table 2. AOGCM experiments used for the present-day (1961-1990) climate validation.

\begin{tabular}{|c|c|c|c|}
\hline Model name Center & Experiment name & Total period & References \\
\hline $\begin{array}{c}\text { ECHAM4/OPYC3 } \\
\text { MPIfM }\end{array}$ & GSDIO & $1860-2049$ & $\begin{array}{c}\text { Roeckner et al. (1999) } \\
\text { Stendel et al. (2002) }\end{array}$ \\
\hline GFDL_R30_c GFDL & GS_C_1 & $1865-2089$ & Delworth et al. (2002) \\
\hline DOE PCM NCAR & Historic Run & $1960-1999$ & Washington et al. (2000) \\
\hline
\end{tabular}


averages, we define two additional MMEs, MME_S1 and MME_S2, which are weighted MMEs similar to Giorgi and Mearns (2002). However, there is a main difference between our weighted MMEs and those of Giorgi and Mearns (2002) in that we use pattern statistics of the present-day climate while they utilized area-averaged values in the present and future periods.

In the previous studies, model selection from AOGCMs or weighting factor calculation for each AOGCM has been evaluated in an independent way for each variable and/or region, e.g., for each grid point. This method might produce physically inconsistent projections and make it difficult to interpret the mechanism in future projection results. In this study, skillful models for construction of MME4 are selected simultaneously based on their performances of present-day climate simulation of both temperature and precipitation. Observational data, which are used for model climate validation, are 1961-1990 mean temperature from the Climate Research Unit (CRU) (Jones 1994; Jones and Moberg 2003) and 1979-1999 mean precipitation from the Climate Prediction Center (CPC) Merged Analysis of Precipitation (CMAP) (Xie and Arkin 1996, 1997).

Temperature and precipitation changes during the 21st century are projected with four MMEs (MME7, MME4, MME_S1, and MME_S2) and their differences are analyzed. Differences between ensemble means and intra-ensemble standard deviations of MME7 and MME4 are analyzed to examine if there is an advantage to use MME4 (MME from selected skillful models) over MME7 (simple average of total member of models) and those between the A2 and B2 results to assess a possible effect of greenhouse gas mitigation. To see whether there is seasonal dependence of climate change over East Asia, monthly and seasonal distributions of temperature and precipitation in the late 21st century are investigated.

\section{Model evaluation}

\subsection{Bias and RMSE}

Because the present-day climate fields of the A2 and B2 simulations with the same AOGCM are very similar to each other, only A2 scenario runs are used for validation. In the bias of the global temperature field, CSIRO Mk2 $\left(+1.1^{\circ} \mathrm{C}\right)$,
DOE PCM $\left(-1.7^{\circ} \mathrm{C}\right)$, and GFDL_R30_c $\left(+1.8^{\circ} \mathrm{C}\right)$ have larger absolute value while CGCM2 $\left(-0.1^{\circ} \mathrm{C}\right), \mathrm{CCSR} / \mathrm{NIES} 2\left(-0.1^{\circ} \mathrm{C}\right)$, and HadCM3 $\left(-0.2^{\circ} \mathrm{C}\right)$ show smaller value. RMSEs of global temperature field have larger values with a range of $2.4-2.9^{\circ} \mathrm{C}$ except for ECHAM4/OPYC3 $\left(1.7^{\circ} \mathrm{C}\right)$ and $\mathrm{HadCM} 3\left(1.9^{\circ} \mathrm{C}\right)$. In the global precipitation, DOE PCM has relatively large bias (+0.4 mm/day) and RMSE ( $1.8 \mathrm{~mm} /$ day $)$ whereas other models have biases with a range of $-0.2-+0.1 \mathrm{~mm} /$ day and RMSEs of $1.0-$ $1.4 \mathrm{~mm} /$ day. Regional biases and RMSEs for the East Asian domain show different behaviors from global values.

Figure 1 shows bias and RMSE distributions of East Asian temperature and precipitation from seven AOGCMs and four MMEs. Most models have negative biases in temperature while positive biases in precipitation exist over East Asia. In the bias distribution (Fig. 1a,b) ECHAM4/OPYC3 has the best skill and other models show similar performances. CGCM2 represents stronger negative bias of $-4^{\circ} \mathrm{C}$ in the temperature but the lowest bias in the precipitation. GFDL_R30_c has the largest precipitation bias but smaller temperature bias. Hence it is difficult to select models of lower performance in the bias field of temperature and precipitation. The RMSE distribution of temperature in Fig. 1c shows that CGCM2 has notably larger value of $6.4^{\circ} \mathrm{C}$ than other models. The RMSE in precipitation is grouped with a range of similar amplitude of 1.0-1.5 mm/day (Fig. 1d). In the model evaluation of East Asian climate simulation using two uncentered statistics (bias and RMSE), it is found that there is not large difference between model performances except for large RMSE and bias of CGCM2 temperature. As a result, the first selection is done as CGCM2 is removed from further consideration of skillful models. Figure 1 also shows that four MMEs have in general an increased performance than the individual models, and that, among four MMEs, MME4 has the best skill in near surface temperature. More comprehensive discussions of MME results are given below.

\subsection{Taylor diagrams}

The Taylor diagram analysis is applied to present-day climate patterns for temperature and precipitation field of seven AOGCMs in 

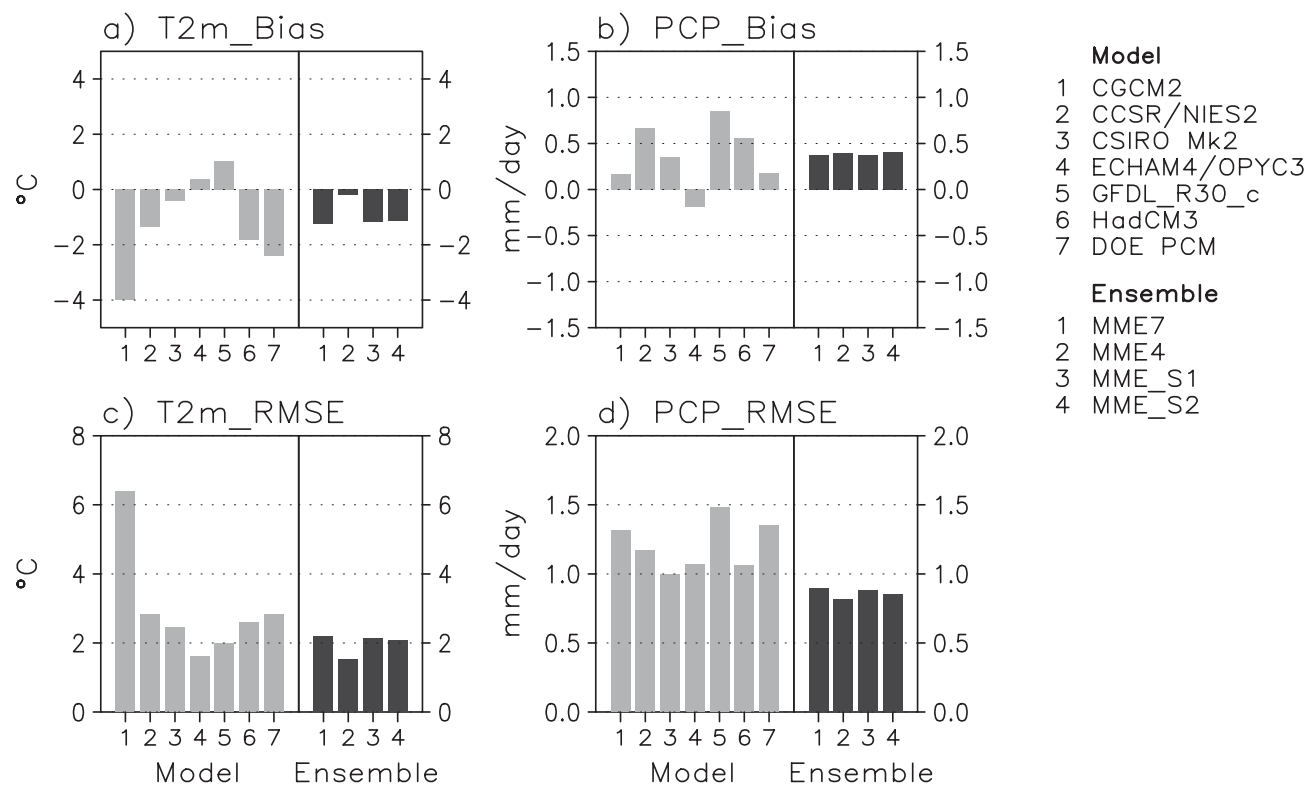

Fig. 1. Bias and RMSE distributions of area-averaged near surface temperature $\left({ }^{\circ} \mathrm{C}\right)$ and precipitation (mm/day) over East Asia for the present-day climate (1961-1990 mean) from seven AOGCM simulations and four MMEs.

order to select skillful models. Figure 2 represents the result of the Taylor diagram analysis for the East Asian temperature and precipitation, and Table 3 lists values of normalized variance ratio $\left(\tilde{\sigma}_{f}\right)$, pattern correlation with observation $(R)$, normalized centered RMSE $\left(\tilde{E}^{\prime}\right)$, and skill scores $S_{1}$ and $S_{2}$ for seven AOGCMs and four MMEs. In the Taylor diagram the radial distance from the origin represents the standard deviation ratio of a tested pattern (model) to that of a reference pattern (observation), the pattern correlation between two fields is given by the azimuthal position, and the normalized centered RMSE of the tested pattern is given by the distance from the reference point of the observations (Taylor 2001). The results of MME_S1 and MME_S2 are not plotted in Fig. 2 because they are located very close to the point of MME7 results in both temperature and precipitation (see Table 3). CGCM2, which exhibited the lowest performance in the bias and RMSE (see Fig. 1), is analyzed in the Taylor diagram and it also reveals the lowest skill scores among seven models in both temperature and precipitation (see Table 3). Apart from CGCM2, CCSR/NIES2 has the lowest skill scores for the East Asian temperature, but the difference from other models is not large (Table 3 ). The Taylor diagram in Fig. 2 shows that six models except for CGCM2 are positioned very close to each other in the temperature performance. On the other hand, precipitation evaluation result shows that, excluding CGCM2, CCSR/NIES2 and DOE PCM have a relatively low skill score in $S_{1}$, and that DOE PCM has an outstandingly lower skill score in $S_{2}$ (Table 3 ). In the Taylor diagram (Fig. 2) one can see the lower performance in the precipitation of DOE PCM ('g' mark). Putting together the results of bias, RMSE, and Taylor diagram analyses, the second model selection is done as DOE PCM and CCSR/NIES2 are removed from models of high performance constituting MME4. Finally, skillful models for MME4 are selected as CSIRO Mk2, ECHAM4/OPYC3, GFDL_R30_c, and HadCM3.

In Table 3 the performances of four MMEs in the present-day climate simulation are compared with the individual models. Generally MMEs have better skills than the individual models. MME_S1 and MME_S2 show similar (or a little higher) performances to MME7, which implies that the weighted MMEs based on centered statistics in the present-day cli- 
Table 3. The normalized standard deviation ratio $\left(\tilde{\sigma}_{f}\right)$, pattern correlation with observation $(R)$, normalized centered RMSE $\left(\tilde{E}^{\prime}\right)$, and skill scores $\left(S_{1}, S_{2}\right)$ in the Taylor diagram analysis for the East Asian temperature and precipitation from seven AOGCM simulations and four MMEs. The asterisks (*) indicate AOGCMs selected for MME4.

\begin{tabular}{|c|c|c|c|c|c|c|c|c|c|c|}
\hline \multirow{2}{*}{ Models } & \multicolumn{9}{|c}{ Temperature } & \multicolumn{4}{c|}{ Precipitation } \\
\cline { 2 - 10 } & $\tilde{\sigma}_{f}$ & $R$ & $\tilde{E}^{\prime}$ & $S_{1}$ & $S_{2}$ & $\tilde{\sigma}_{f}$ & $R$ & $\tilde{E}^{\prime}$ & $S_{1}$ & $S_{2}$ \\
\hline CGCM2 & 1.351 & 0.908 & 0.610 & 0.873 & 0.758 & 0.644 & 0.569 & 0.826 & 0.650 & 0.314 \\
\hline CCSR/NIES2 & 1.193 & 0.978 & 0.300 & 0.959 & 0.928 & 0.664 & 0.808 & 0.607 & 0.768 & 0.567 \\
\hline CSIRO Mk2* & 1.178 & 0.977 & 0.293 & 0.962 & 0.930 & 0.748 & 0.811 & 0.588 & 0.833 & 0.619 \\
\hline ECHAM4/OPYC3* & 1.101 & 0.988 & 0.191 & 0.985 & 0.967 & 0.810 & 0.750 & 0.664 & 0.837 & 0.561 \\
\hline GFDL_R30_c* & 1.086 & 0.984 & 0.205 & 0.985 & 0.962 & 1.128 & 0.746 & 0.768 & 0.860 & 0.572 \\
\hline HadCM3* & 1.144 & 0.987 & 0.225 & 0.976 & 0.957 & 1.246 & 0.893 & 0.572 & 0.902 & 0.765 \\
\hline DOE PCM & 1.074 & 0.988 & 0.177 & 0.989 & 0.971 & 0.865 & 0.597 & 0.846 & 0.782 & 0.398 \\
\hline MME7 & 1.142 & 0.987 & 0.223 & 0.976 & 0.957 & 0.760 & 0.863 & 0.516 & 0.865 & 0.699 \\
\hline MME4 & 1.119 & 0.991 & 0.185 & 0.983 & 0.970 & 0.887 & 0.893 & 0.450 & 0.933 & 0.791 \\
\hline MME_S1 & 1.139 & 0.988 & 0.216 & 0.977 & 0.960 & 0.774 & 0.870 & 0.502 & 0.876 & 0.716 \\
\hline MME_S2 & 1.137 & 0.989 & 0.209 & 0.978 & 0.962 & 0.795 & 0.885 & 0.474 & 0.895 & 0.749 \\
\hline
\end{tabular}

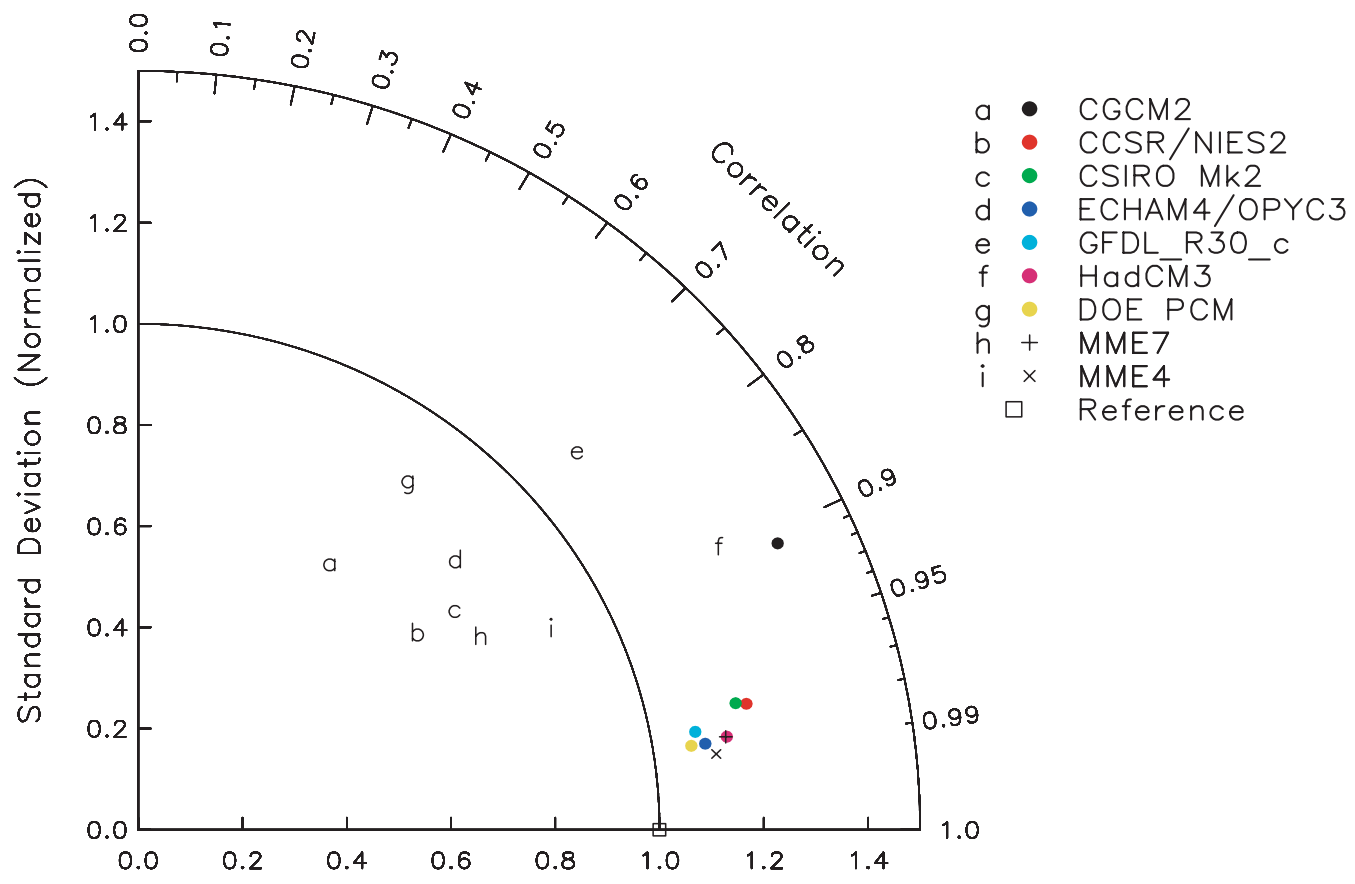

Fig. 2. Taylor diagram analysis for model-simulated near surface temperature and precipitation over East Asia for the present-day period (1961-1990) from seven AOGCM simulations, MME7, and MME4. Symbols [alphabets] depict temperature [precipitation] results. 

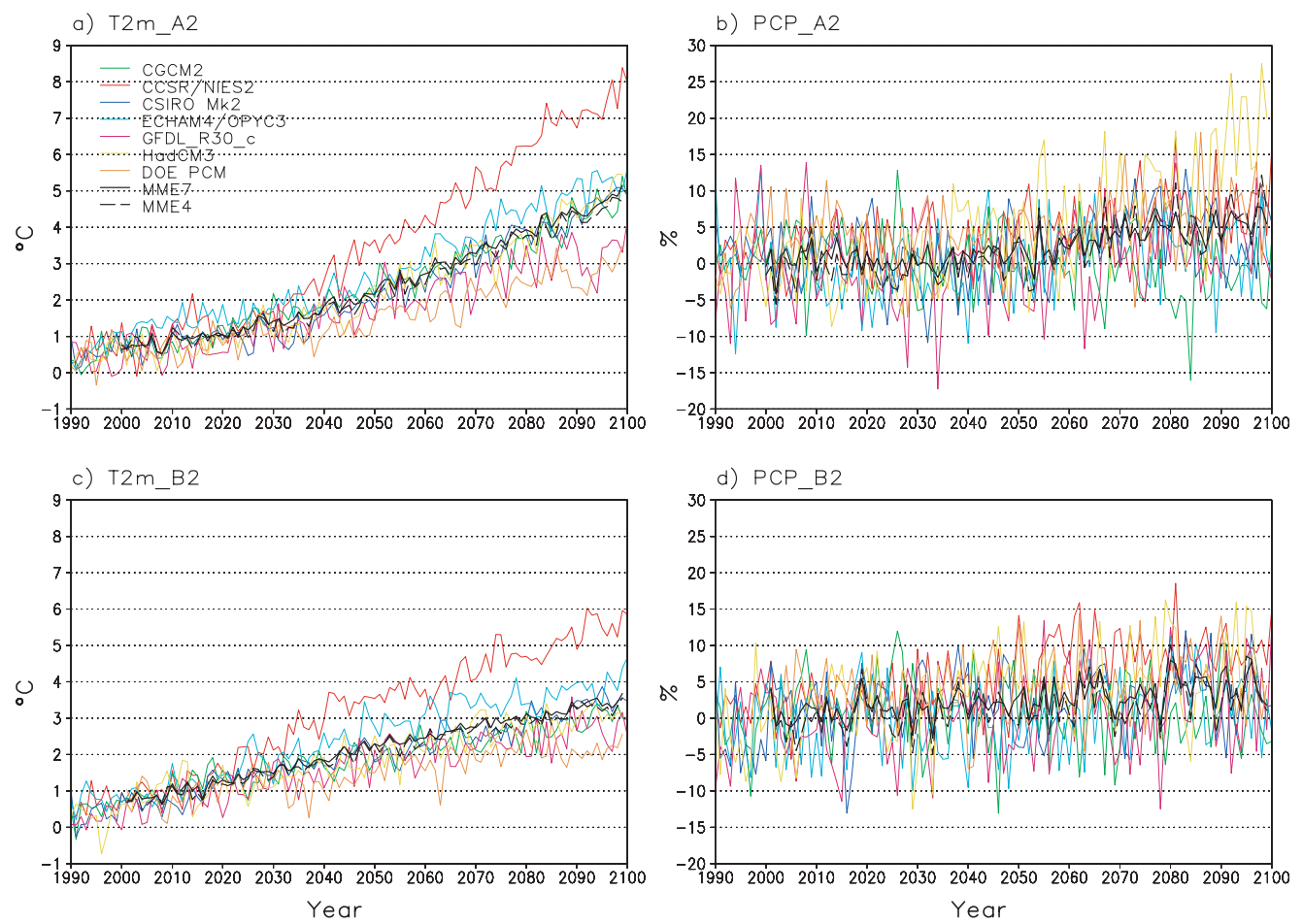

Fig. 3. Time series of East Asian area-averaged temperature $\left({ }^{\circ} \mathrm{C}\right)$ and precipitation change $(\%)$ with respective to 1961-1990 mean in seven AOGCM simulations, MME7, and MME4 for the SRES A2 (upper panels) and B2 (lower) scenarios.

mate do not have significant advantage over the simple arithmetic averaging. It is notable that MME4 exhibits better skill than the other MMEs as in the bias and RMSE analysis in Fig. 1. The Taylor diagram in Fig. 2 supports the result showing that the position of MME4 is closer to the reference point than the individual models and other MMEs.

\section{Projection results}

\subsection{Area average}

a. Temperature

Figure 3a,c show the annual time series of area-averaged East Asian temperature change relative to 1961-1990 mean in the A2 and B2 scenario simulations of seven AOGCMs, MME7, and MME4. The results of MME_S1 and MME_S2 are omitted in Fig. 3 because they display very similar behavior to MME7 (compare mean values in Table 4). All model simulations and MMEs predict the temperature increase, which is larger than global mean and the internal and inter-model variabilities in
East Asian temperature are also larger than those in global mean (see Fig. 9.6a of Cubasch et al. 2001). Table 4 summarizes the temperature changes in the $\mathrm{A} 2$ and $\mathrm{B} 2$ simulations of seven AOGCMs and four MMEs for three 30 -year periods of 2020s (2010-2039), 2050s (2040-2069), and 2080s (2070-2099) including intra-ensemble standard deviations for MME7 and MME4. MME7 of the A2 [B2] scenario indicates East Asian temperature increase of 1.2 [1.4], 2.5 [2.4], $4.1^{\circ} \mathrm{C}\left[3.2^{\circ} \mathrm{C}\right]$ for $2020 \mathrm{~s}, 2050 \mathrm{~s}$, and 2080s, respectively (for reference, global mean temperature increases are 1.0 [1.0], 1.9 $\left.[1.8], 3.3^{\circ} \mathrm{C}\left[2.5^{\circ} \mathrm{C}\right]\right)$. The reason why the $\mathrm{B} 2$ temperature increase is $0.2^{\circ} \mathrm{C}$ larger than the A2 scenario in 2020s might be because the aerosol cooling effect is larger in the A2 scenario than in the B2 for that period while GHG emissions are similar (Stendel et al. 2002; Cubasch et al. 2001). The similar result is obtained in the global temperature, but the global temperature increase in $2020 \mathrm{~s}$ is $0.08^{\circ} \mathrm{C}$ larger in the B2 scenario than in the A2. The distri- 
Table 4. Area-averaged near surface temperature changes $\left({ }^{\circ} \mathrm{C}\right)$ over East Asia during 2020 s $(2010-$ 2039), 2050s (2040-2069), and 2080s (2070-2099) from seven AOGCM simulations under the IPCC SRES A2 and B2 scenarios and four MMEs. The asterisks (*) indicate AOGCMs selected for MME4.

\begin{tabular}{|c|c|c|c|c|c|c|c|}
\hline \multirow{2}{*}{\multicolumn{2}{|c|}{ Model }} & \multicolumn{2}{|c|}{2020 s (2010-2039) } & \multicolumn{2}{|c|}{2050 s $(2040-2079)$} & \multicolumn{2}{|c|}{ 2080s (2070-2099) } \\
\hline & & $\mathrm{A} 2$ & $\mathrm{~B} 2$ & $\mathrm{~A} 2$ & $\mathrm{~B} 2$ & $\mathrm{~A} 2$ & $\mathrm{~B} 2$ \\
\hline \multicolumn{2}{|c|}{ CGCM2 } & 1.35 & 1.46 & 2.54 & 2.05 & 3.95 & 2.74 \\
\hline \multicolumn{2}{|c|}{ CCSR/NIES2 } & 1.59 & 1.91 & 3.81 & 3.71 & 6.57 & 5.04 \\
\hline \multicolumn{2}{|c|}{ CSIRO Mk2* } & 1.04 & 1.35 & 2.25 & 2.17 & 4.04 & 3.05 \\
\hline \multicolumn{2}{|c|}{ ECHAM4/OPYC3* } & 1.67 & 1.63 & 2.85 & 2.91 & 4.68 & 3.63 \\
\hline \multicolumn{2}{|c|}{ GFDL_R30_c* } & 0.99 & 1.12 & 2.03 & 1.93 & 3.05 & 2.53 \\
\hline \multicolumn{2}{|c|}{ HadCM3* } & 1.09 & 1.22 & 2.36 & 2.08 & 4.12 & 2.94 \\
\hline \multicolumn{2}{|c|}{ DOE PCM } & 0.97 & 1.11 & 1.58 & 1.60 & 2.58 & 2.12 \\
\hline \multirow{2}{*}{ MME7 } & Mean & 1.24 & 1.40 & 2.49 & 2.35 & 4.14 & 3.15 \\
\hline & Std Dev & 0.29 & 0.29 & 0.71 & 0.72 & 1.28 & 0.95 \\
\hline \multirow{2}{*}{ MME4 } & Mean & 1.20 & 1.33 & 2.37 & 2.27 & 3.97 & 3.04 \\
\hline & Std Dev & 0.32 & 0.22 & 0.35 & 0.44 & 0.68 & 0.45 \\
\hline MME_S1 & Mean & 1.24 & 1.40 & 2.48 & 2.35 & 4.13 & 3.15 \\
\hline MME_S2 & Mean & 1.24 & 1.40 & 2.48 & 2.35 & 4.13 & 3.15 \\
\hline
\end{tabular}

bution of aerosol emissions is spatially inhomogeneous in contrast to well-mixed GHGs and the East Asian region is one of large emission areas, so the aerosol cooling effect will be larger than the global mean (Mitchell and Johns 1997). The inter-model variability (intraensemble standard deviation) in the East Asian temperature change for the $\mathrm{A} 2$ [B2] scenario is 0.3 [0.3], $0.7[0.7]$, and $1.3^{\circ} \mathrm{C}\left[1.0^{\circ} \mathrm{C}\right]$ during 2020s, 2050s, and 2080s, respectively, which is almost twice larger than global values (not shown). However, ensemble mean change (signal) is three times larger than inter-model variability (noise) in the East Asian temperature projections.

In Fig. 3a,c, MME4 mean temperature series, depicted by thick dotted line, show little difference from MME7. Temperature changes of MME4 for the A2 [B2] scenario in 2020s, 2050s, and $2080 \mathrm{~s}$ are 1.2 [1.3], 2.4 [2.3], and $4.0^{\circ} \mathrm{C}$ $\left[3.0^{\circ} \mathrm{C}\right]$, respectively, which are about $0.1-0.2^{\circ} \mathrm{C}$ smaller than MME7 (Table 4). However, intermodel standard deviations of MME4 for 2050s and 2080s are about a half of those of MME7.
Figure 4a,c show the ensemble mean and standard deviation of MME7 and MME4 for East Asian temperatures based on the A2 and B2 scenarios. It is clearly shown that model uncertainties in the East Asian temperature change are smaller in MME4 than in MME7. This demonstrates that MME4 has an advantage of intensifying signal to noise ratio (SNR) twice of MME7 in 2050s and 2080s, and that the MME from skillful models can make more significant signals in the projection of areaaveraged East Asian temperature change.

\section{b. Precipitation}

The time series of area-averaged East Asian precipitation changes (\%) relative to the present-day climate (1961-1990 mean) in the A2 and B2 scenario simulations of seven AOGCMs, MME7, and MME4 are shown in Fig. 3b,d. The MME_S1 and MME_S2 results are left out since they are very close to the MME7 result in Fig. 3 (see also Table 5). The East Asian precipitation exhibits an increasing trend in most models, more dominantly in the 

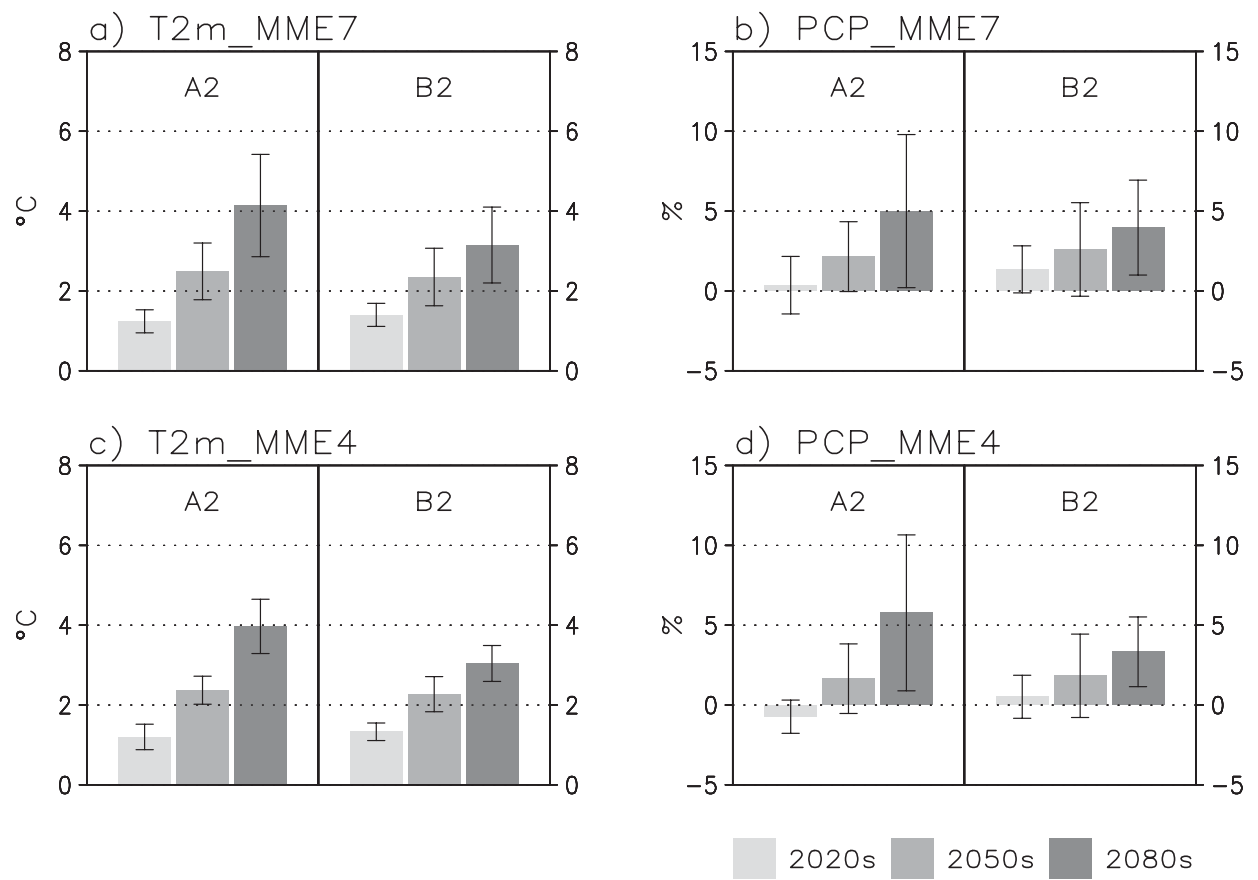

Fig. 4. East Asian area-averaged temperature $\left({ }^{\circ} \mathrm{C}\right)$ and precipitation changes (\%) (bar) during $2020 \mathrm{~s}$ (2010-2039), 2050s (2040-2069), and 2080s (2070-2099) and their inter-model variability (error bar) from MME7 and MME4 for the SRES A2 and B2 scenarios. Changes are relative to 19611990 mean.

Table 5. Same as Table 4 except for precipitation change (\%).

\begin{tabular}{|c|c|c|c|c|c|c|c|}
\hline \multirow{2}{*}{\multicolumn{2}{|c|}{ Model }} & \multicolumn{2}{|c|}{ 2020s (2010-2039) } & \multicolumn{2}{|c|}{ 2050s (2040-2079) } & \multicolumn{2}{|c|}{2080 s (2070-2099) } \\
\hline & & $\mathrm{A} 2$ & B2 & $\mathrm{A} 2$ & B2 & $\mathrm{A} 2$ & B2 \\
\hline \multicolumn{2}{|c|}{ CGCM2 } & 0.40 & 1.60 & -0.03 & 0.06 & -2.37 & 0.65 \\
\hline \multicolumn{2}{|c|}{ CCSR/NIES2 } & 1.49 & 2.92 & 4.44 & 7.21 & 7.33 & 8.98 \\
\hline \multicolumn{2}{|c|}{ CSIRO Mk2* } & 0.12 & 1.55 & 1.34 & 1.61 & 4.96 & 2.80 \\
\hline \multicolumn{2}{|c|}{ ECHAM4/OPYC3* } & -2.05 & -0.62 & 1.42 & -0.65 & 2.71 & 2.43 \\
\hline \multicolumn{2}{|c|}{ GFDL_R30_c* } & -1.06 & -0.66 & -0.73 & 0.87 & 2.51 & 1.57 \\
\hline \multicolumn{2}{|c|}{ HadCM3* } & 0.07 & 1.82 & 4.56 & 5.48 & 12.89 & 6.50 \\
\hline \multicolumn{2}{|c|}{ DOE PCM } & 3.55 & 2.86 & 4.03 & 3.65 & 6.99 & 4.85 \\
\hline \multirow{2}{*}{ MME7 } & Mean & 0.36 & 1.35 & 2.15 & 2.60 & 5.00 & 3.97 \\
\hline & Std Dev & 1.80 & 1.47 & 2.19 & 2.93 & 4.79 & 2.97 \\
\hline \multirow{2}{*}{ MME4 } & Mean & -0.73 & 0.52 & 1.65 & 1.83 & 5.77 & 3.33 \\
\hline & Std Dev & 1.04 & 1.35 & 2.18 & 2.61 & 4.88 & 2.18 \\
\hline MME_S1 & Mean & 0.30 & 1.31 & 2.19 & 2.65 & 5.28 & 4.03 \\
\hline MME_S2 & Mean & 0.20 & 1.30 & 2.32 & 2.87 & 5.82 & 4.27 \\
\hline
\end{tabular}


A2 scenario, but the trend is not clearer than the global precipitation increase (Fig. 9.6b of Cubasch et al. 2001). It might be caused by the fact that the internal and inter-model variabilities are larger in the regional precipitation than in the global precipitation. The increase of natural noise in the regional precipitation also appears more dominant than in the regional temperature. A2 scenario results in Fig. 3b show a little decreasing trend up to $\sim 2035$, which might be related to stronger aerosol forcing in the A2 scenario than in the B2, but further analysis is required (also see discussion below). Precipitation changes in the A2 and B2 simulations of seven AOGCMs and four MMEs for three 30-year periods are given in Table 5 . The MME7 A2 [B2] result predicts East Asian precipitation increase of 0.4 [1.4], 2.2 [2.6], and $5.0 \%$ [4.0\%] for $2020 \mathrm{~s}, 2050 \mathrm{~s}$, and $2080 \mathrm{~s}$, respectively while global mean changes are 1.1 [1.4], 2.3 [2.6], and 4.4\% [3.7\%] increases. Precipitation increases in East Asia are 0.4-1.0\% larger in the B2 scenario than in the A2 for the periods of 2020 s and 2050 s, which is consistent with the global result. This seems to be related to the enhanced direct cooling effect of aerosols in the A2 scenario compared with the B2 scenario in the mid 21st century (Cubasch et al. 2001). However, the indirect effect of aerosols on clouds can be another important factor (Penner et al. 2001), so more detailed analyses are required for future works. The inter-model standard deviations in the East Asian precipitation projections using the MME7 A2 [B2] scenarios are 1.8 [1.5], 2.2 [2.9], and 4.8\% [3.0\%] for $2020 \mathrm{~s}, 2050 \mathrm{~s}$, and 2080s, which is more than twice of those in the global mean precipitation projections (not shown). This implies that noise is as large as signal in the East Asian precipitation change, indicating a very large model uncertainty in the projection of regional precipitation changes.

The MME4 mean precipitation shows a very similar trend to MME7 (Fig. 3b,d). Table 5 shows that precipitation changes of MME4 for the A2 [B2] scenario are -0.7 [0.5], 1.7 [1.8], $5.8 \%$ [3.3\%] in $2020 \mathrm{~s}, 2050 \mathrm{~s}$, and $2080 \mathrm{~s}$, respectively, which are about $0.5-1.1 \%$ smaller than MME7 except for the A2 result of 2080s. The precipitation projections of MME_S1 and MME_S2 reveal less difference $(0.1-0.8 \%)$ from MME7. The comparison of inter-model stan- dard deviations shows that MME4 has similar amplitude of inter-model uncertainty to that of MME7 but for the A2 scenario in 2020s and the B2 scenario in 2080s (Table 5). Figure 4b,d represent means and intra-ensemble standard deviations of MME7 and MME4 for East Asian precipitation changes for three 30-year periods. Both ensemble mean and inter-model variability of MME4 have little difference from those of MME7. The advantage of MME4 does not appear in the precipitation projections in contrast to the marked noise reduction in the temperature projections (Fig. 4a,c).

\subsection{Spatial patterns \\ a. Temperature}

Figure 5 shows spatial patterns of East Asian temperature change and inter-model variability for the three 30-year periods of 2020s, 2050s, and 2080s using MME7 for the A2 scenario. The ensemble mean value is defined as signal and the standard deviation is as noise following Cubasch et al. (2001). The area where signal is larger than noise $(\mathrm{SNR}>1)$ is shaded in the mean field of Fig. 5a,c,e. Larger temperature increase appears in higher latitude than in lower latitude and in land than in ocean, which gets stronger as time. Horizontal patterns of the inter-model variability shown in Fig. 5b,d,f are also characterized by larger values in higher latitude, but more zonal pattern and smaller amplitude than ensemble means. The fact that all area of ensemble mean fields is shaded in all 30-year periods, represents that the GHG signal is larger than the intermodel uncertainty in the East Asian temperature projections. Spatial patterns of temperature change for the B2 scenario have similar spatial patterns to the A2 results except for a little different amplitude (figure not shown). More detailed analysis of comparing the A2 results with the B2 is done below.

\section{b. Precipitation}

Horizontal distributions of ensemble mean change and intra-ensemble standard deviation of the precipitation change for the MME7 A2 scenario are shown in Fig. 6. As in the temperature pattern of Fig. 5, the area where SNR $>1$ is shaded in the mean field of Fig. 6a,c,e. Precipitation patterns are similar to temperature patterns in Fig. 5 showing that larger increase 

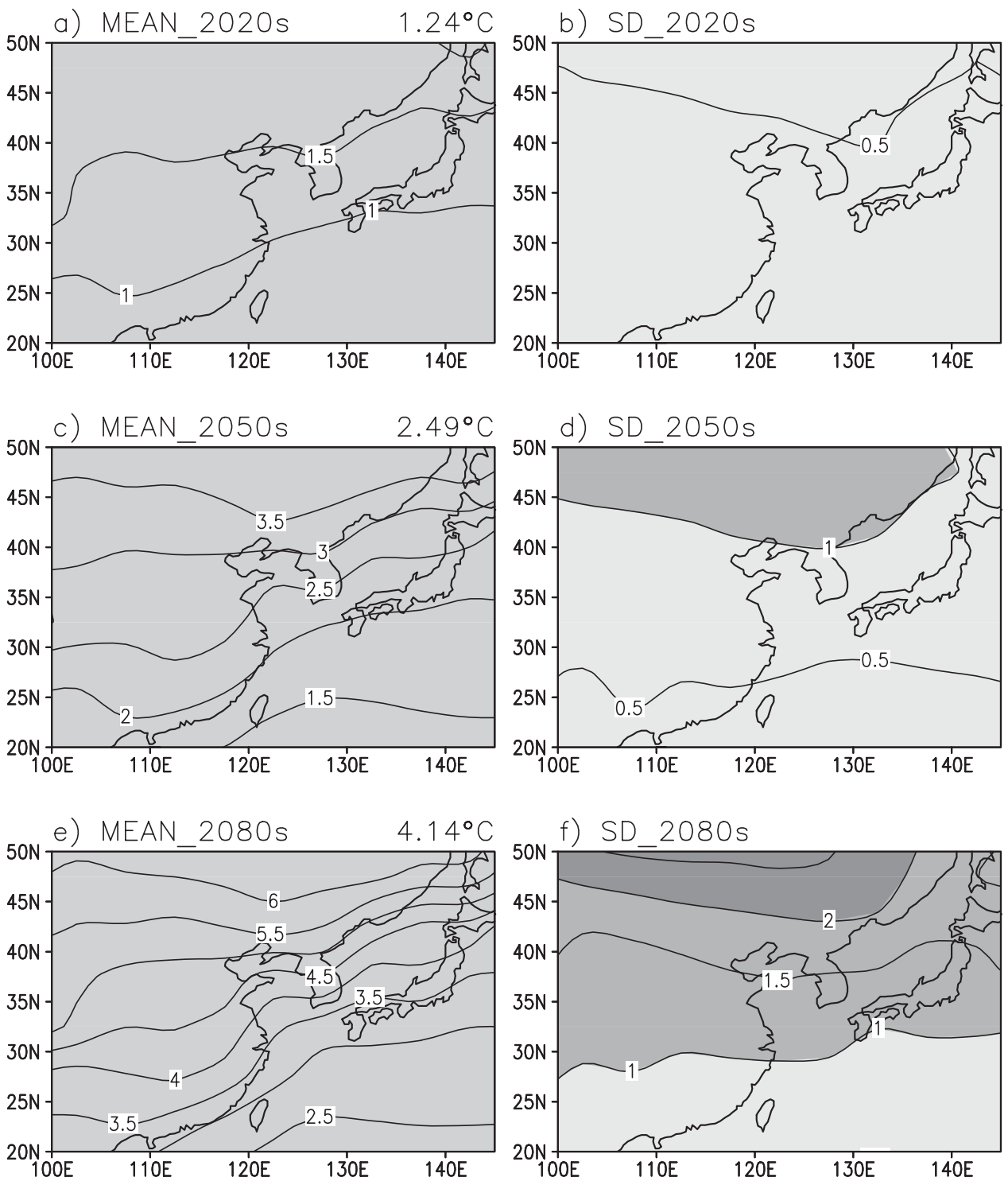

Fig. 5. Multi-model ensemble mean of near surface temperature changes (left panels) and intra-ensemble standard deviations (SD) (right panels) in MME7 for the SRES A2 scenario for three 30year periods of 2020s (2010-2039), 2050s (2040-2069), and 2080s (2070-2099). In the mean field, changes are relative to the 30-year mean of 1961-1990, the area where ensemble mean is greater than standard deviation (inter-model variability) is shaded, and area-averaged values are depicted at the right top.

in higher latitude land than in lower latitude ocean. Stronger inter-model variability appears in the continental area of $35-45^{\circ} \mathrm{N}$ in $2080 \mathrm{~s}$, which is known as one of active cyclogenesis in East Asia (Chen et al. 1991) and the entrance region of storm track in the North Pacific (Chang 2001; Harnik and Chang 2003). In contrast to the temperature field, notable signals of precipitation change relative to the intermodel noise appear only in land area north of $30^{\circ} \mathrm{N}$ in $2080 \mathrm{~s}$, demonstrating the large uncertainty and the low reliability in the precipitation projections. The precipitation pattern of mean and variability for the B2 scenario is not largely different from the A2 result as in the case of temperature (figure not shown). 

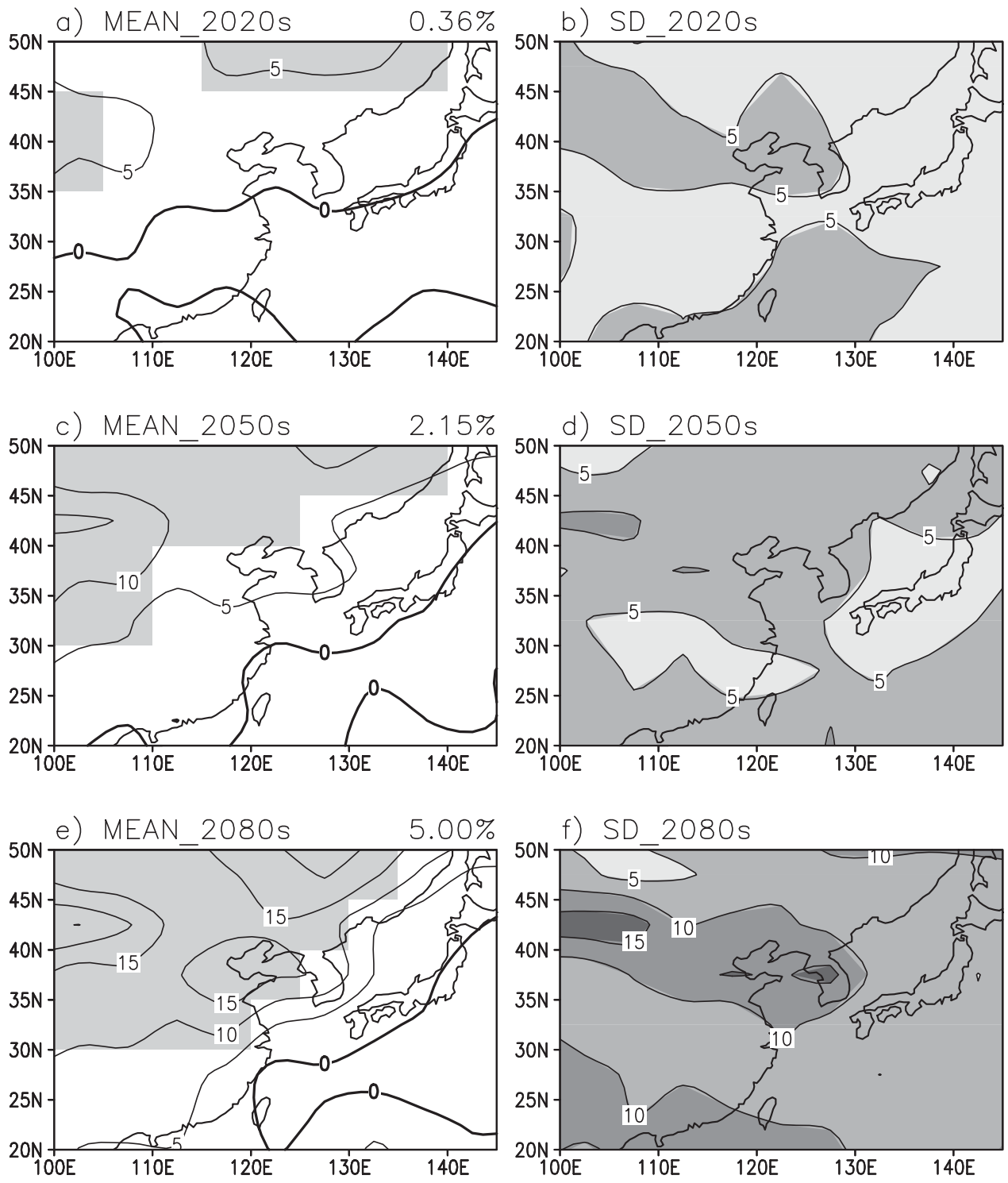

Fig. 6. Same as Fig. 5 but for precipitation (\%).

\section{c. Difference between MME4 and MME7 results}

In order to see if MME4 constructed by selected skillful models has an advantage over MME7 in the pattern projections, we compare ensemble mean and inter-model variability of MME4 with those of MME7. The comparison of MME_S1 and MME_S2 mean with MME7 mean is not shown because their projection results are very close to MME7. Figure 7 represents temperature comparisons of MME4 with
MME7. The difference between MME4 and MME7 (MME4-MME7) is used for the ensemble mean comparison (Fig. 7a,c,e) while the ratio of standard deviation (MME4/MME7) is shown for the comparison of the inter-model variability (Fig. $7 \mathrm{~b}, \mathrm{~d}, \mathrm{f}$ ). In the mean field MME4 and MME7 have a difference of amplitude from -0.4 to $+0.6^{\circ} \mathrm{C}$ in 2080 s (Fig. 7e), which is very small compared to the large temperature change of $2.5-6^{\circ} \mathrm{C}$ (Fig. 5e). Regional mean difference is also small with amplitude of 

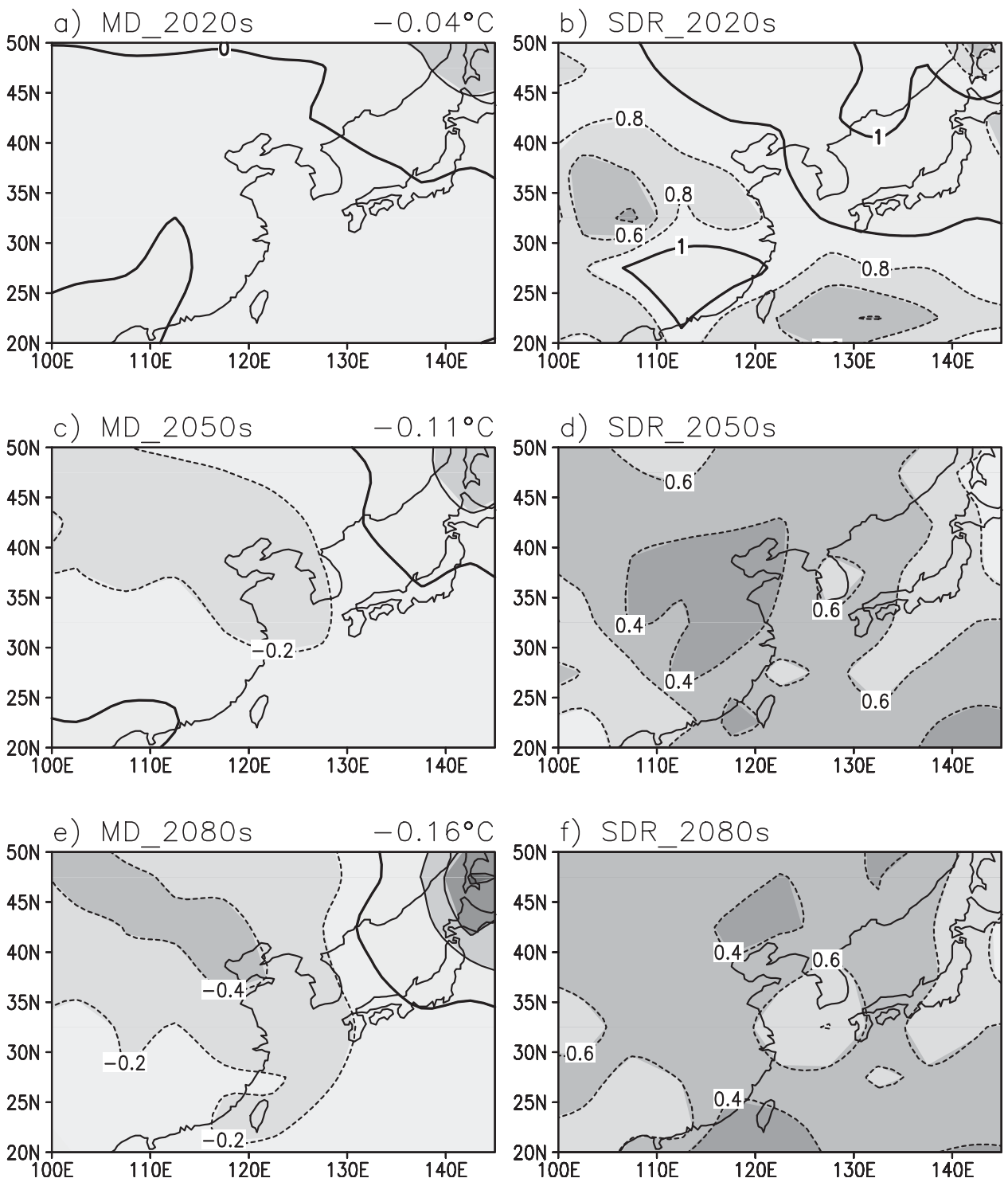

Fig. 7. Comparison of near surface temperature changes in MME4 with MME7 for the SRES A2 scenario simulations during 2020s (2010-2039), 2050s (2040-2069), and 2080s (2070-2099): Multi-model ensemble mean difference (MD) of temperature change (MME4 minus MME7, left panels) and intra-ensemble standard deviation ratio (SDR) (MME4 divided by MME7, right panels). Area-averaged values are depicted at the right top of the MD fields.

$0.16^{\circ} \mathrm{C}$ in $2080 \mathrm{~s}$ (Table 4 ). In the variability comparison the ratio of standard deviation has $0.4-0.8$ in $2050 \mathrm{~s}$ and $2080 \mathrm{~s}$ (Fig. 7d,f). This indicates that the inter-model noise is reduced when skillful models are used to construct MME. The comparison of MME4 and MME7 for the B2 scenario shows very similar results to the A2 result except that the difference between MME4 and MME7 is reduced in the mean field of 2020 s and 2050 s in the B2 scenario (figure not shown).

Precipitation changes of MME4 and MME7 are compared in Fig. 8. Difference of ensemble means (MME4-MME7) has a range from -2 to $+10 \%$ in 2080 s with larger values in southwest China and East Manchuria (Fig. 8e). This difference is not small considering that the amplitude of precipitation change is $0-20 \%$ in 2080 s 

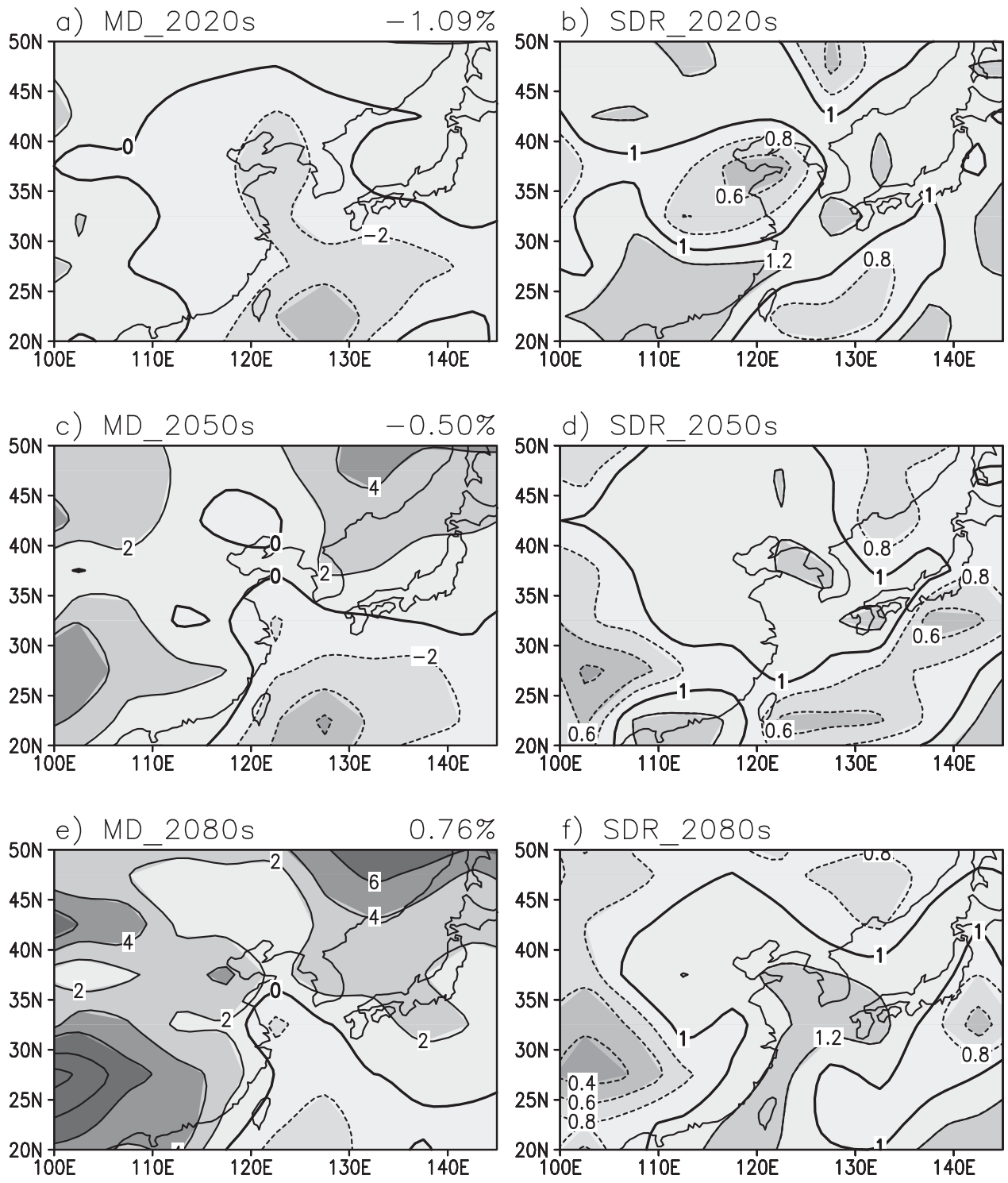

Fig. 8. Same as Fig. 7 but for precipitation.

(Fig. 6e). The comparison of the standard deviation of MME4 with MME7 is represented by their ratio (MME4/MME7). The area of similar variability with ratios of $0.8-1.2$ appears extensively in 2050 s and 2080s (Fig. 8d,f). It means that there is no significant advantage of reducing the inter-model noise when using MME4 over MME7. The precipitation comparison result for the B2 result shows that the ensemble mean difference between MME4 and MME7 in 2050s and 2080s is a little bit smaller than the A2 result, but that overall patterns are very similar to the A2 results (figure not shown).

\subsection{Potential impact of $G H G$ mitigation: A2 minus $B 2$}

The difference between the simulations based on the A2 and B2 scenarios can provide a potential impact of GHG mitigation, especially in 2050 s and 2080s because aerosols play a more important role than GHGs in making such a difference in 2020s (Stendel et al. 2002). Figure 9 shows the difference between temperature 

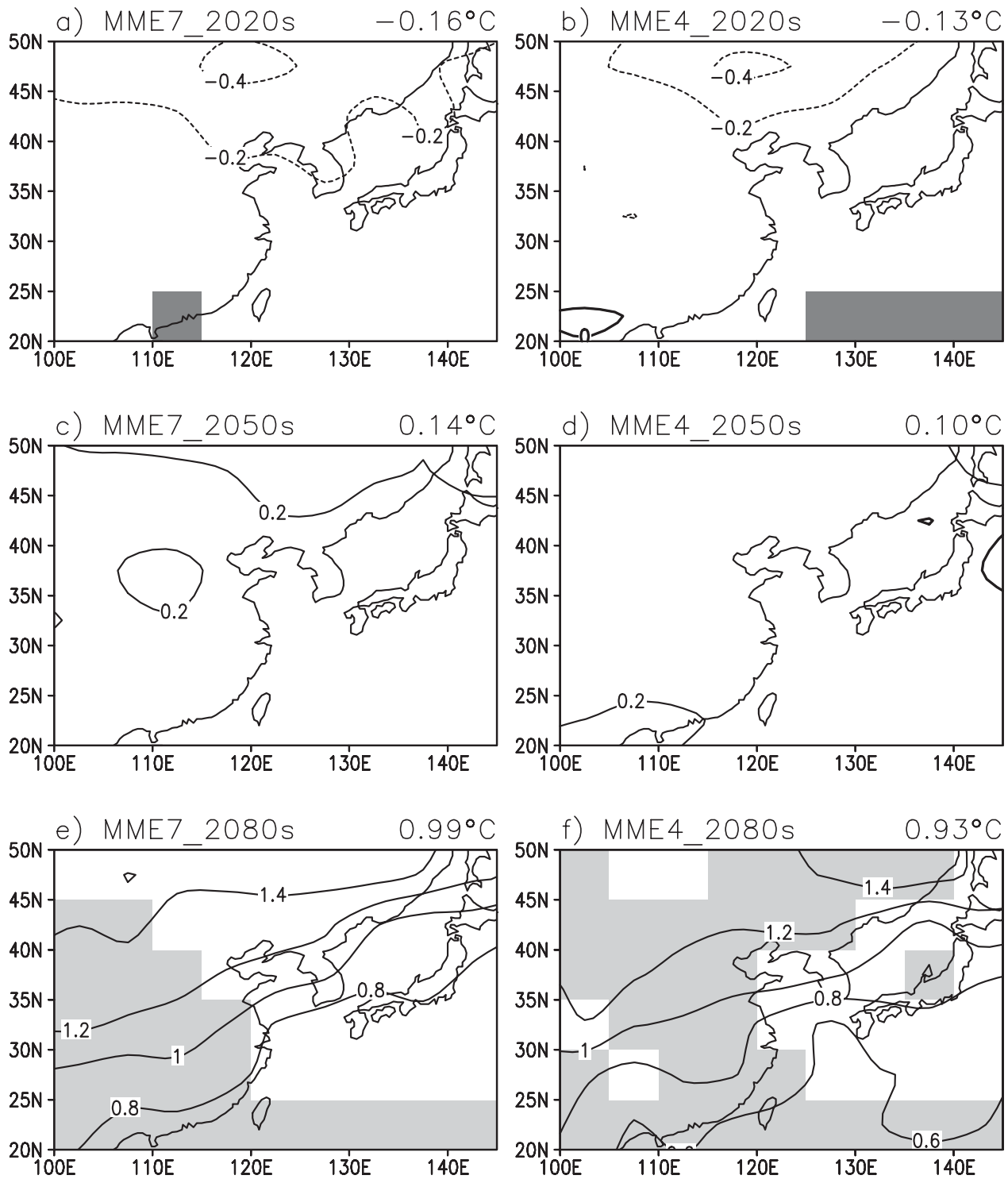

Fig. 9. SRES A2 minus B2 scenario results for near surface temperature projections $\left({ }^{\circ} \mathrm{C}\right)$ in $\mathrm{MME} 7$ (left panels) and MME4 (right panels) for three 30-year periods of 2020s (2010-2039), 2050s (2040-2069), and 2080s (2070-2099). Light [dark] shadings indicate areas of statistically significant positive [negative] difference (one-sided $\mathrm{T}$ test at $95 \%$ confidence level). Area-averaged value is depicted at the right top of each panel.

projections from the A2 and B2 scenarios for MME7 and MME4. Statistically significant differences are searched for by one-sided $\mathrm{T}$ test with $5 \%$ significant level and are depicted by shadings. The A2-B2 result of MME7 shows negative values over all East Asia in 2020s, which is mainly caused by the stronger aerosol cooling in the A2 scenario (Fig. 9a) as discussed above, while positive values appear in 2050s and 2080s (Fig. 9c,e). The temperature increase of the A2 scenario in 2050s is larger than the B2 scenario (area-average $0.1^{\circ} \mathrm{C}$ ) but not statistically significant (Fig. 9c). The A2-B2 in 2080 s is statistically significant over the central and southern China and the oceanic area south of $25^{\circ} \mathrm{N}$ with a regional average of $1.0^{\circ} \mathrm{C}$ (Fig. 9e). This demonstrates that the potential impact of GHG mitigation in the East Asian 

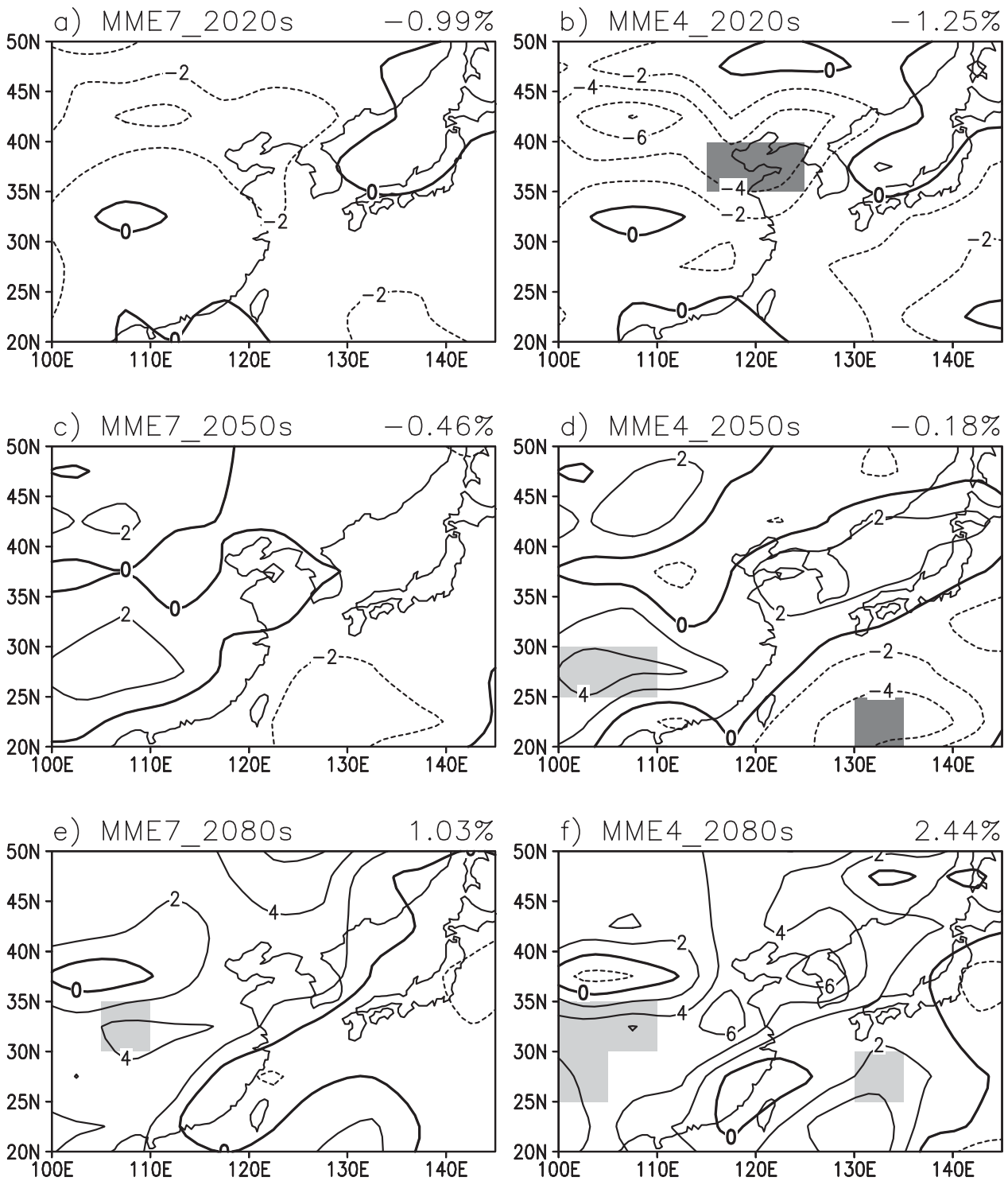

Fig. 10. Same as Fig. 9 but for precipitation projections (\%).

warming appears only in the late 21st century over the southern area if the concentrations of GHG are successfully controlled along the levels of the SRES B2 scenario. The A2-B2 results of MME4 are alike in the pattern and amplitude to those of MME7 (Fig. 9b,d,f). However, it is shown that the area of significant difference in 2080s of MME4 is broader than in MME7 (Fig. 9f), including almost all the continental area, which mainly results from the reduced inter-model variability in MME4 than in MME7 (Fig. 7f).
The A2-B2 in the precipitation change over East Asia is given in Fig. 10. The MME7 result in Fig. 10a,c,e shows that regional average value of $\mathrm{A} 2-\mathrm{B} 2$ is $-1.0,-0.5$, and $1.0 \%$ in $2020 \mathrm{~s}, 2050$, and $2080 \mathrm{~s}$, and that statistically significant difference cannot be found in all periods. It is shown that, unlike the temperature result in Fig. 9, the potential impact of GHG mitigation on the precipitation change is not clear because of the large inter-model difference. The MME4 result of A2-B2 in Fig. 10b,d,f shows that the amplitude of differences be- 

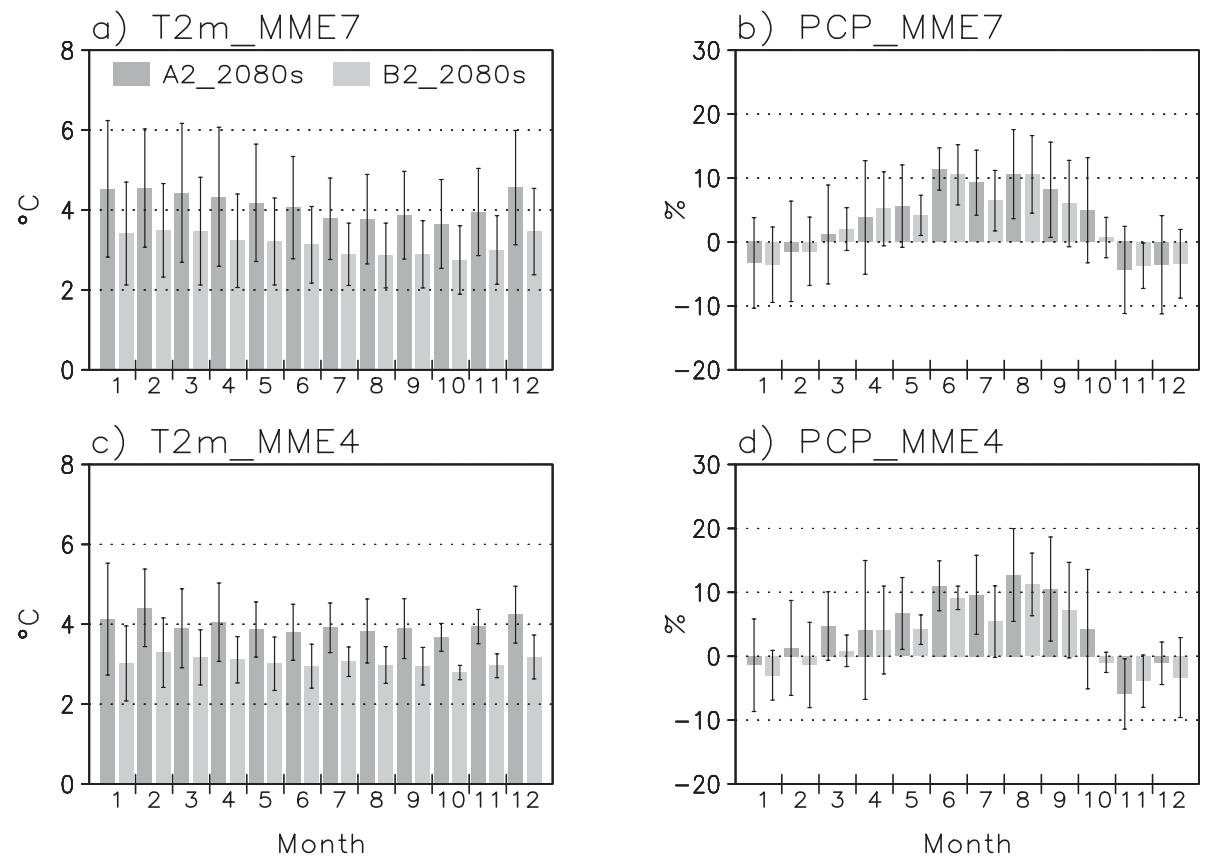

Fig. 11. Monthly mean change of area-averaged near surface temperature $\left({ }^{\circ} \mathrm{C}\right)$ and precipitation $(\%)$ over East Asia during 2080s (2070-2099) in MME7 and MME4 for the SRES A2 and B2 scenarios. Changes are relative to 1961-1990 mean. Inter-model variability (intra-ensemble standard deviation) for each monthly mean is depicted by error bar.

comes larger than MME7 and the statistically significant area appears over southern China in 2050 s and 2080s. Area-averaged precipitation differences of A2-B2 in MME4 are $-1.3,-0.2$, and $2.4 \%$ for $2020 \mathrm{~s}, 2050 \mathrm{~s}$, and $2080 \mathrm{~s}$, respectively. This indicates the high dependence of future projections of precipitation change on the selected models and the necessity of efforts to improve models for better simulations of precipitation patterns. Relatively notable impact of GHG mitigation on precipitation change is the reduction of precipitation increase over the southern China region. It should be noted that, in the precipitation field, the area of notable change (continent north of $30^{\circ} \mathrm{N}$, Fig. 6e) does not correspond to the area of significant GHG mitigation impact (southern China, Fig. 10f).

\subsection{Seasonal dependence of climate change}

In order to examine the seasonal dependence of the East Asian climate change, monthly distributions of area-averaged East Asian temperature and precipitation change in 2080s are presented in Fig. 11 for MME7 and MME4. The $\mathrm{A} 2$ and $\mathrm{B} 2$ results are also compared and the error bars depict the range of uncertainty from model difference for each month. It shows that monthly mean temperature change and its uncertainty range are larger in December to April than in June to November, which is irrespective of selected scenarios and MMEs (Fig. 11a,c). As a whole, the A2 scenario results have larger temperature increases than B2 scenario results. As in the annual mean case in Fig. 4, MME4 has an advantage of less uncertainty range in monthly temperature change over MME7. However, this seasonal dependence in the temperature change is not clear because of a relatively large and overlapped inter-model variability between months. Monthly precipitation change shows more characteristic feature of seasonal dependence than temperature (Fig. $11 b, d)$. Precipitation increases in the warmer season (April to September) while it decreases in the cooler season (November to February). Especially the precipitation increase in summer is a common characteristic through most 
models, i.e. significant over inter-model noise, but precipitation decrease in the cooler season is not clear compared to the inter-model variability.

To search for geographical characteristics of seasonal climate change necessary to the impact assessment of regional climate change, horizontal patterns of temperature and precipitation changes are analyzed for each season. Figure 12 shows the MME7 result of seasonal change in 2080s for the A2 scenario. The area where SNR $>1$ is depicted by shadings as in Fig. 5 and Fig. 6. The amplitude of temperature change (signal) is larger than the inter-model variability (noise) over East Asia and in all seasons (Fig. 12). It is worthwhile to note that the temperature change over the oceanic area is seldom varied with season, but the continental temperature increases more in winter and spring than in summer and autumn. Accordingly, the horizontal temperature gradient between ocean and continent gets weaker in 2080s than in the present-day (1961-1990), especially in winter and spring (Fig. 14), which may weaken East Asian winter monsoon system (Hu et al. 2000a).

In the seasonal precipitation patterns, strong GHG signal areas (SNR > 1) exhibit different features with season (Fig. 12). Area-averaged precipitation change is $-2.8,4.5,10.5$, and $3.6 \%$ in winter, spring, summer, and autumn, respectively (also compare with monthly precipitation change of Fig. 11b,d). The precipitation in winter increases in the continental area north of $30^{\circ} \mathrm{N}$ while it decreases over the oceanic area south of Japan, suggesting the northward shift of the frontal zone by global warming ( $\mathrm{Hu}$ et al. 2000a). The overall pattern of precipitation change in spring is similar to that in winter, but the amplitude of precipitation increase is smaller and the precipitation decrease of oceanic area moves toward the Philippine Sea. It should be noted that the real amount of precipitation increase would not be strong in winter and spring because the area of precipitation increase exhibits small precipitation in the present-day simulations (Fig. 14b).

The precipitation change in summer is positive over all East Asia with a maximum change of 30\% near the Korean Peninsula and Yellow Sea (Fig. 12f). This area of large precipitation increase in summer is known to have a heavy rainfall above $6 \mathrm{~mm} /$ day in the present-day observations (Fig. 13f), but most AOGCMs constituting MME7 produce much less precipitation (i.e. negative bias) over the area than observations (Fig. 14f). Therefore, the interpretation of the future precipitation increase in summer should be done very carefully although its signal is stronger than inter-model uncertainty. A strong signal cannot be found in the precipitation change in autumn relative to inter-model noise (Fig. 12h). In contrast to the low performance in summer precipitation, the performance of the MME simulation of seasonal temperature fields is quite good except for the notable cold bias in the northern continental area in winter and spring (Fig. 13, Fig. 14).

\section{Conclusion and discussions}

The 21st century climate changes over East Asia are projected from multi-model ensembles (MMEs) of seven AOGCM simulations based on IPCC SRES A2 and B2 scenarios. Analyses of East Asian climate change from MMEs show that East Asia is likely to experience warmer and wetter climate in the 21st century than present with larger amplitude than global mean. Temperature change signal is larger than inter-model noise while there is a large noise in the projection of precipitation change. The MME from four selected AOGCMs (MME4) does not provide different projection result from MME7, but reduces the inter-model uncertainties in temperature projections in the late 21st century. The skill-weighted MMEs based on centered statistics in the Taylor analysis exhibit very similar projection result to MME7. A potential impact of greenhouse gas mitigation inferred from A2 minus $\mathrm{B} 2$ results becomes more discernable in the temperature change during the late 21st century, but not in precipitation change. Monthly to seasonal dependence of climate change over East Asia is characterized by the larger increase of winter temperature and summer precipitation. Temperature increase in winter is dominated in the continental area north of $30^{\circ} \mathrm{N}$, while summer precipitation increase appears along the coastal area with a maximum near the Korean Peninsula. However, it should be noted that large uncertainty remains in the projection results originating from the low model performance in the simulation of summer precipitation. Also it 


\section{MME7 A2 2080s}
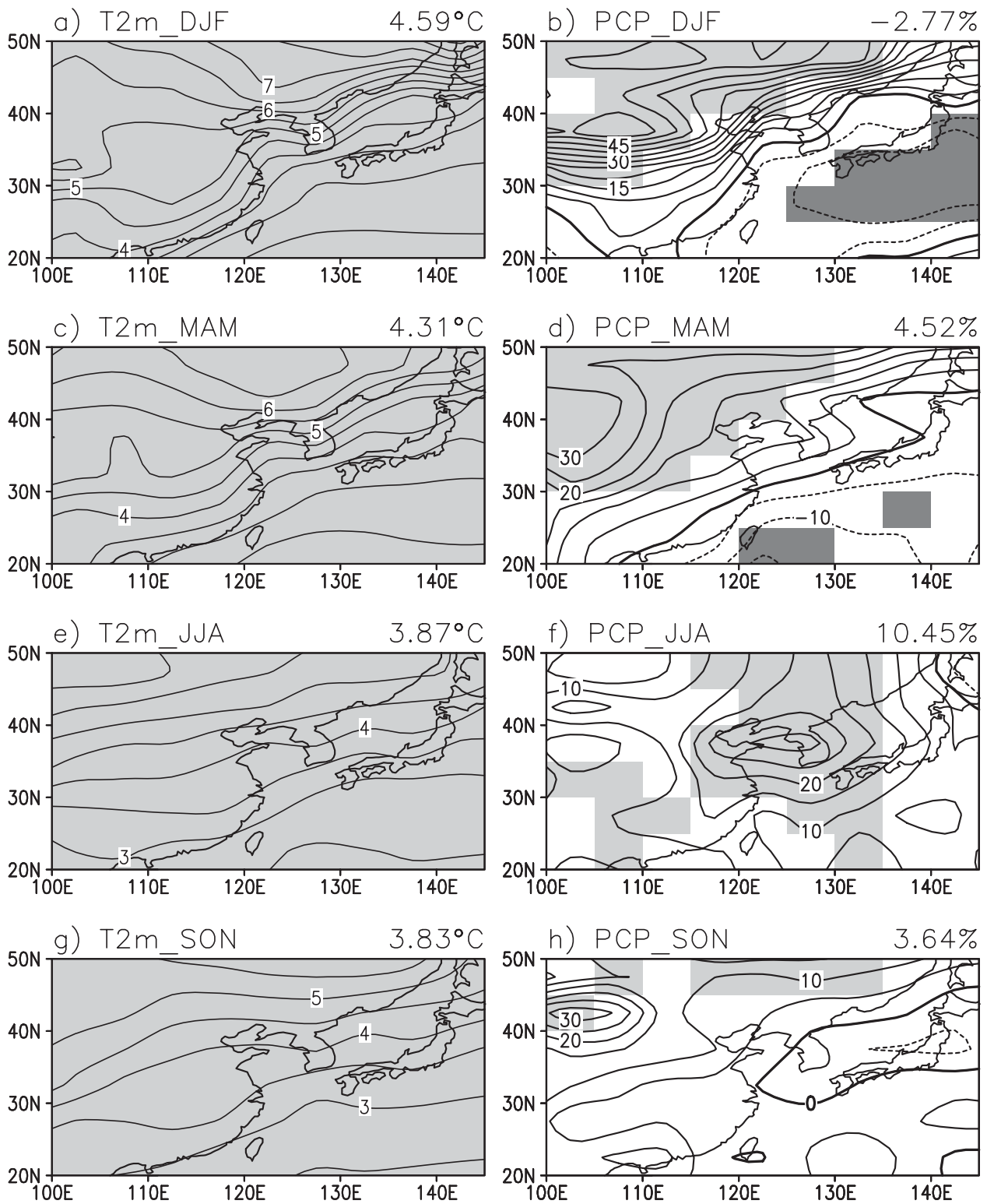

Fig. 12. Seasonal changes of near surface temperature $\left({ }^{\circ} \mathrm{C}\right)$ and precipitation $(\%)$ in $\mathrm{MME} 7$ for the SRES A2 scenario during 2080s (2070-2099). Changes are relative to the 30-year mean of 19611990. Light [dark] shadings indicate areas of SNR $>1$ for positive [negative] changes. Area-averaged value is depicted at the right top of each panel.

should be kept in mind that four AOGCMs selected for MME4 are not the best models in the world scientific community, since the samples are limited to the models available in IPCC DDC.
In the previous studies, MME method is normally constructed for each variable applied. In this study, we use more comprehensive method via selecting skillful model evaluating model performance simultaneously for temperature 


\section{Observations}
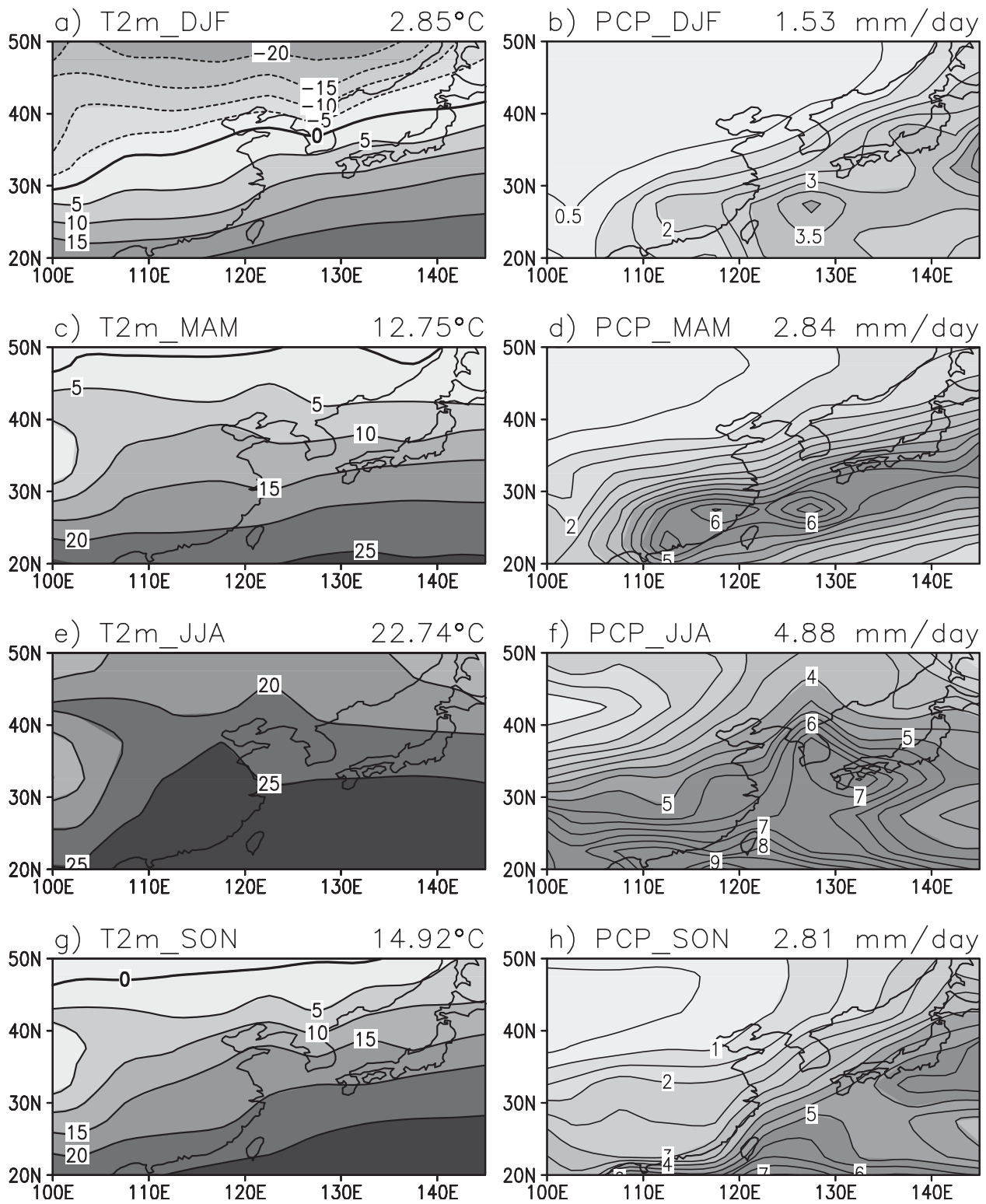

Fig. 13. Seasonal mean near surface temperature $\left({ }^{\circ} \mathrm{C}\right)$ and precipitation $(\mathrm{mm} /$ day) distributions of the observations. Note that CMAP precipitations are interpolated into $5^{\circ} \times 5^{\circ}$ grids. Area-averaged value is depicted at the right top of each panel.

and precipitation simulations. However, spatial similarity is considered only, and the evaluation of space-time structure is necessary in the future study. This might be helpful to reduce uncertainties from inter-model variability, especially in the precipitation projection, and pro- duce more reliable projections of future regional climate change.

The result of this study indicates a possible change of East Asian monsoon system by global warming. In the previous studies, an enhanced land-sea contrast and a northward shift of the 


\section{MME7 1961-1990}
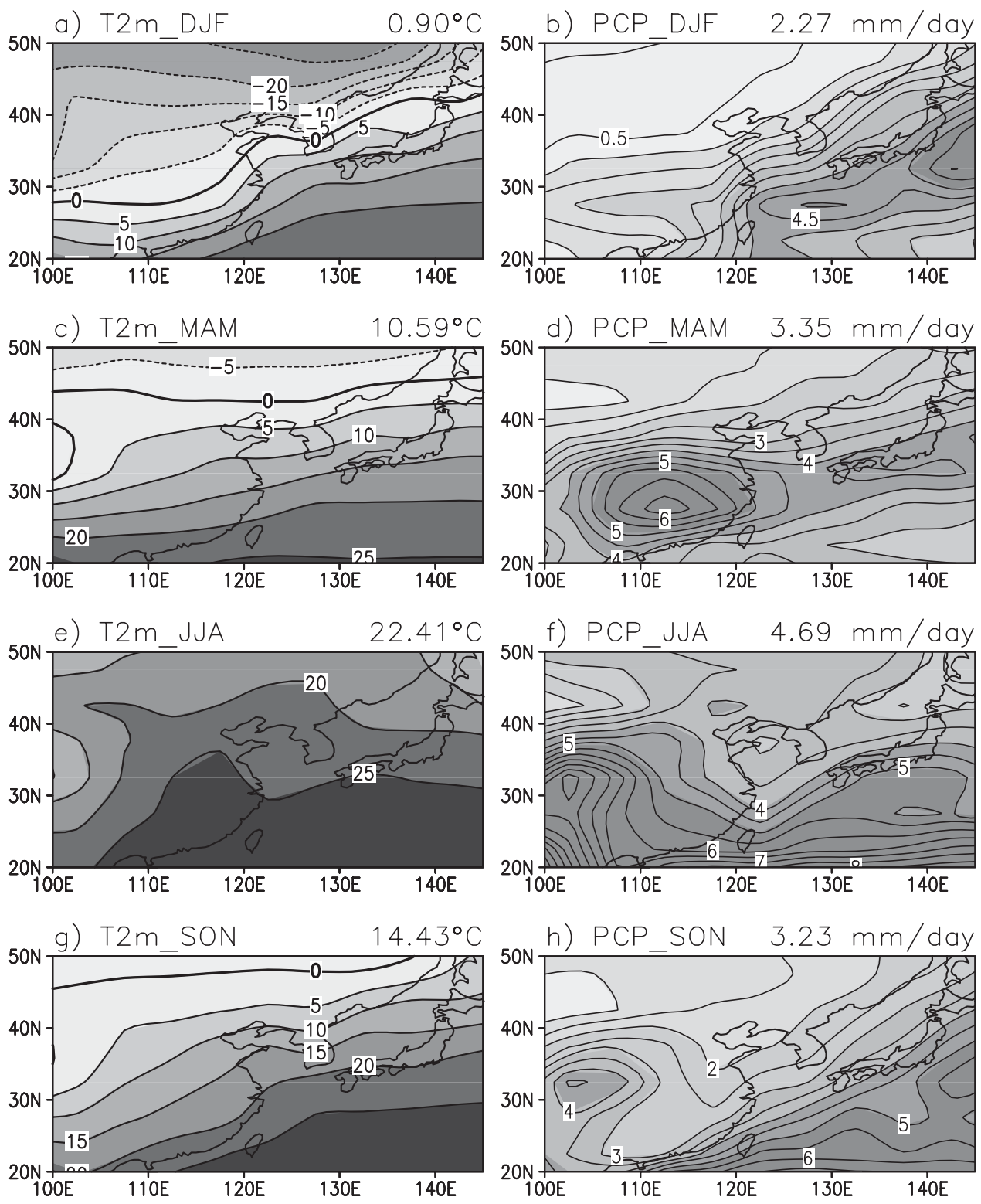

Fig. 14. Same as Fig. 13 but MME7 mean for the present-day period (1961-1990).

convergence zone are proposed as a possible mechanism of the intensified Asian summer monsoon ( $\mathrm{Hu}$ et al. 2000b; Kitoh et al. 1997) and the northward and eastward shift and weakening of the East Asian trough are analyzed as the cause of the weakening of the Asian winter monsoon in the global warming scenario (Hu et al. 2000a). However, their re- sults are based on the simulations from a single model and they can be different from model to model, that is, model-dependent. Mechanism of monsoon change should be more intensively investigated using MME methods in the context of seasonal cycle change in the future work. Especially, contributions of convective and large-scale precipitation to the total pre- 
cipitation change should be analyzed over East Asia (e.g., Noda and Tokioka 1989).

In this paper, MME projections using AOGCMs with coarse resolution of $5^{\circ} \times 5^{\circ}$ are provided, so climate features of higher resolution such as an orographic effect on precipitation distribution cannot be analyzed in the results. In this context, the MME method can be applied to time-slice experiments using highresolution AGCM (Cubasch et al. 1995; Timbal et al. 1997; May and Roeckner 2001) and simulations from various Regional Climate Models (RCMs) as a more promising way (e.g., Hirakuchi and Giorgi 1995; Kato et al. 2001 for East Asia). Finally, the change of pattern and intensity of extreme events including floods and droughts should be examined (e.g., Meehl et al. 2000; Kharin and Zwiers 2000; Palmer and Rälsänen 2002; Milly et al. 2002) considering its high impacts on society and spatial and temporal linkage within the East Asian region (Min et al. 2003; Qian et al. 2003).

\section{Acknowledgments}

The authors appreciate Dr. Seita Emori and two anonymous reviewers for their helpful comments and suggestions on our manuscript. This research was performed for the project of the Korean Meteorological Research Institute, "Research on the Development of Regional Climate Change Scenarios to Prepare the National Climate Change Report".

\section{References}

Arakawa, A., 1972: Design of the UCLA general circulation model. Tech. Report No. 7, Department of Meteorology, University of California at Los Angeles, $116 \mathrm{pp}$.

Boer, G.J. and S.J. Lambert, 2001: Second-order space-time climate difference statistics. Clim. Dyn., 17, 213-218.

Chang, E.K.M., 2001: GCM and observational diagnoses of the seasonal and interannual variations of the Pacific storm track during the cool season. J. Atmos. Sci., 58, 1784-1800.

Chen, S.-J., Y.-H. Kuo, P.-Z. Zhang and Q.-F. Bai, 1991: Synoptic climatology of cyclogenesis over East Asia. 1958-1987. Mon. Wea. Rev., 119, 1407-1418.

Cubasch, U., G.A. Meehl, G.J. Boer, R.J. Stouffer, M. Diz, A. Noda, C.A. Senior, S. Raper and K.S. Yap, 2001: Projections of future climate change. In: Climate Change 2001: The Scien- tific Basis. Contribution of Working Group I to the Third Assessment Report of the Intergovernmental Panel on Climate Change [Houghton, J.T., Y. Ding, D.J. Griggs, M. Noguer, P.J. van der Linden, X. Dai, K. Maskell and C.A. Johnson (eds.)]. Cambridge University Press, UK, 944 pp.

- J. Waszkewitz, G. Hegerl and J. Perlwitz, 1995: Regional climate change as simulated in time-slice experiments. Clim. Change, 31, 273304.

Dai, A., G.A. Meehl, W.M. Washington, T.M.L. Wigley and J.M. Arblaster, 2001: Ensemble simulation of twenty-first century climate changes: Business-as-usual versus $\mathrm{CO}_{2}$ stabilization. Bull. Amer. Meteor. Soc., 82, 2377-2388.

Delworth, T.L., R.J. Stouffer, K.W. Dixon, M.J. Spelman, T.R. Knutson, A.J. Broccoli, P.J. Kushner and R.T. Wetherald, 2002: Review of simulations of climate variability and change with the GFDL R30 coupled climate model. Clim. Dyn., 19, 555-574.

Flato, G.M. and G.J. Boer, 2001: Warming asymmetry in climate change simulations. Geophys. Res. Lett., 28, 195-198.

Gillett, N.P., F.W. Zwiers, A.J. Weaver, G.C. Hegerl, M.R. Allen and P.A. Stott, 2002: Detecting anthropogenic influence with a multi-model ensemble. Geophys. Res. Lett., 29(20), 1970, doi:10.1029/2002GL015836.

Giorgi, F. and L.O. Mearns, 2002: Calculation of average, uncertainty range, and reliability of regional climate changes from AOGCM simulations via the "Reliability Ensemble Averaging" (REA) method. J. Climate, 15, 1141-1158.

Gordon, H.B. and S.P. O'Farrell, 1997: Transient climate change in the CSIRO coupled model with dynamics sea ice. Mon. Wea. Rev., 125, 875907.

Gregory, D. and P.R.R. Rowntree, 1990: A mass flux convection scheme with representation of cloud ensemble characteristics and stability dependent closure. Mon. Wea. Rev., 118, 1483-1506.

, R. Kershaw and P.M. Inness, 1997: Parameterization of momentum transport by convection. II: Tests in single column and general circulation models. Quart. J. Roy. Meteor. Soc., 123, 1153-1183.

Harnik, N. and E.K.M. Chang, 2003: Storm track variations as seen in radiosonde observations and reanalysis data. J. Climate, 16, 480-495.

Hirakuchi, H. and F. Giorgi, 1995: Multiyear present-day and $2 \times \mathrm{CO}_{2}$ simulations of monsoon climate over eastern Asia and Japan with a regional climate model nested in a general circulation model. J. Geophys. Res., 100, 21105-21125. 
Hu, Z.-Z., L. Bengtsson and K. Arpe, 2000a: Impact of global warming on the Asian winter monsoon in a coupled GCM. J. Geophys. Res., 105, 4607-4624.

-, M. Latif, E. Roeckner and L. Bengtsson, 2000b: Intensified Asian summer monsoon and its variability in a coupled model forced by increasing greenhouse gas concentrations. Geophys. Res. Lett., 27, 2681-2684.

Johns, T.C., J.M. Gregory, W.J. Ingram, C.E. Johnson, A. Jones, J.A. Lowe, J.F.B. Mitchell, D.L. Roberts, D.M.H. Sexton, D.S. Stevenson, S.F.B. Tett and M.J. Woodage, 2003: Anthropogenic climate change for 1860 to 2100 simulated with the HadCM3 model under updated emissions scenarios. Clim. Dyn., 20, 583-612.

Jones, P.D., 1994: Hemispheric surface air temperature variations: a reanalysis and an update to 1993. J. Climate, 7, 1794-1802.

_ scale surface air temperature variations: an extensive revision and an update to 2001. J. Climate, 16, 206-223.

Kato, H., K. Nishizawa, H. Hirakuchi, S. Kadokura, N. Oshima and F. Giorgi, 2001: Performance of RegCM2.5/NCAR-CSM Nested System for the simulation of climate change in East Asia caused by global warming. J. Meteor. Soc. Japan, 79, 99-121.

Kharin, V.V. and F.W. Zwiers, 2000: Changes in the extremes in an ensemble of transient climate simulations with a coupled atmosphere-ocean GCM. J. Climate, 13, 3760-3788.

$\longrightarrow$ and $\longrightarrow$ 2002: Climate predictions with multi-model ensembles. J. Climate, 15, 793799.

Kitoh, A., S. Yukimoto, A. Noda and T. Motoi, 1997: Simulated changes in the Asian summer monsoon at times of increased atmospheric $\mathrm{CO}_{2} . J$. Meteor. Soc. Japan, 75, 1019-1031.

Krishnamurti, T.N., C.M. Kishtawal, Z. Zhang, T. LaRow, D. Bachiochi, E. Williford, S. Gadgil and S. Surendran, 2000: Multimodel ensemble forecasts for weather and seasonal climate. $J$. Climate, 13, 4196-4216.

Lal, M. and H. Harasawa, 2000: Comparison of the present-day climate simulation over Asia in selected coupled atmosphere-ocean global climate models. J. Meteor. Soc. Japan, 78, 871-879. - and - 2001: Future climate change scenarios for Asia as inferred from selected coupled atmosphere-ocean global climate models. J. Meteor. Soc. Japan, 79, 219-227.

Manabe, S., J. Smagorinsky and R.F. Strickler, 1965: Simulated climatology of a general circulation model with a hydrologic cycle. Mon. Wea. Rev., 93, 769-798.
May, W. and E. Roeckner, 2001: A time-slice experiment with the ECHAM4 AGCM at high resolution: The impact of horizontal resolution on annual mean climate change. Clim. Dyn., 17, 407-420.

McAvaney, B.J., C. Covey, S. Joussaume, V. Kattsov, A. Kitoh, W. Ogana, A.J. Pitman, A.J. Weaver, R.A. Wood and Z.-C. Zhao, 2001: Model evaluation. In: Climate Change 2001: The Scientific Basis. Contribution of Working Group I to the Third Assessment Report of the Intergovernmental Panel on Climate Change [Houghton, J.T., Y. Ding, D.J. Griggs, M. Noguer, P.J. van der Linden, X. Dai, K. Maskell and C.A. Johnson (eds.)]. Cambridge University Press, UK, 944 pp.

Meehl, G.A., F. Zwiers, J. Evans, T. Knutson, L. Mearns and P. Whetton, 2000: Trends in extreme weather and climate events: Issues related to modeling extremes in projections of future climate change. Bull. Amer. Meteor. Soc., 81, 427-436.

Milly, P.C.D., R.T. Wetherald, K.A. Dunne and T.L. Delworth, 2002: Increasing risk of great floods in a changing climate. Nature, 415, 514-517.

Min, S.-K., W.-T. Kwon, E.-H. Park and Y. Choi, 2003: Spatial and temporal comparisons of droughts over Korea with East Asia. Int. J. Climatol., 23, 223-233.

Mitchell, J.F.B. and T.C. Johns, 1997: On the modification of global warming by sulphate aerosols. J. Climate, 10, 245-267.

, D.J. Karoly, G.C. Hegerl, F.W. Zwiers, M.R. Allen and J. Marengo, 2001: Detection of climate change and attribution of causes. In: $\mathrm{Cli}$ mate Change 2001: The Scientific Basis. Contribution of Working Group I to the Third Assessment Report of the Intergovernmental Panel on Climate Change [Houghton, J.T., Y. Ding, D.J. Griggs, M. Noguer, P.J. van der Linden, X. Dai, K. Maskell and C.A. Johnson (eds.)]. Cambridge University Press, UK, 944 pp.

Moorthi, S. and M.J. Suarez, 1992: Relaxed Arakawa-Schubert: A parameterization of moist convection for general circulation models. Mon. Wea. Rev., 120, 978-1002.

Nakicenovic, N. and R. Swart (eds.), 2000: Special Report on Emissions Scenarios. Cambridge University Press, Cambridge, United Kingdom, $612 \mathrm{pp}$.

Noda, A. and T. Tokioka, 1989: The effect of doubling the $\mathrm{CO}_{2}$ concentration on convective and nonconvective precipitation in a general circulation model coupled with a simple mixed layer ocean model. J. Meteor. Soc. Japan, 67, 10571069 . 
Nordeng, T.E., 1994: Extended versions of the convective parameterization scheme at ECMWF and their impact on the mean and transient activity of the model in the tropics. ECMWF Research Department, Technical Memorandum No. 206, October 1994, 41 pp.

Nozawa, T., S. Emori, A. Numaguti, Y. Tsushima, T. Takemura, T. Nakajima, A. Abe-Ouchi and M. Kimoto, 2001: Projections of future climate change in the 21st century simulated by the CCSR/NIES CGCM under the IPCC SRES scenario. In: Present and Future of Modeling Global Environmental Change-Toward Integrated Modeling, T. Matsuno and H. Kida, Eds., Terra Scientific Publishing Company, 15-28.

Palmer, T.N. and J. Rälsänen, 2002: Quantifying the risk of extreme seasonal precipitation events in a changing climate. Nature, 145, 512-514.

Penner, J.E., M. Andreae, H. Annegarn, L. Barrie, J. Feichter, D. Hegg, A. Jayaraman, R. Leaitch, D. Murphy, J. Nganga and G. Pitari, 2001: Aerosols, their direct and indirect effects. In: Climate Change 2001: The Scientific Basis. Contribution of Working Group I to the Third Assessment Report of the Intergovernmental Panel on Climate Change [Houghton, J.T., Y. Ding, D.J. Griggs, M. Noguer, P.J. van der Linden, X. Dai, K. Maskell and C.A. Johnson (eds.)]. Cambridge University Press, UK, 944 pp.

Pepper, W.J., J. Leggett, R. Swart, J. Wasson, J. Edmonds and I. Mintzer, 1992: Emissions scenarios for the IPCC. An update: Assumptions, methodology, and results: Support Document for Chapter A3. In: Climate Change 1992: Supplementary Report to the IPCC Scientific Assessment [Houghton, J.T., B.A. Callandar and S.K. Varney (eds.)]. Cambridge University Press, UK, 205 pp.

Qian, W., Q. Hu, Y. Zhu and D.-K. Lee, 2003: Centennial-scale dry-wet variations in East Asia. Clim. Dyn., 21, 77-89.

Roeckner, E., L. Bengtsson, J. Feicher, J. Lelivld and H. Rodhe, 1999: Transient climtae change with a coupled atmosphere-ocean GCM including the tropospheric sulfur cycle. J. Climate, 12, 3004-3032.

Stendel, M., T. Schmith, E. Roeckner and U. Cubasch, 2002: The climate of the 21st century: Transient simulations with a coupled atmosphere-ocean general circulation model. Revised version, Climate Centre Report 02-1, Danish Meteorological Institute, Denmark, 50 $\mathrm{pp}$.

Taylor, K.E., 2001: Summarizing multiple aspects of model performance in a single diagram. J. Geophys. Res., 106, 7183-7192.

Tiedtke, M., 1989: A comprehensive mass flux scheme for cumulus parameterization in largescale models. Mon. Wea. Rev., 117, 1779-1800.

Timbal, B., J.-F. Mahfouf, J.-F. Royer, U. Cubasch and J.M. Murphy, 1997: Comparison between doubled $\mathrm{CO}_{2}$ time-slice and coupled experiments. J. Climate, 10, 1463-1469.

Washington, W.M., J.W. Weatherly, G.A. Meehl, A.J. Semtner Jr., T.W. Bettge, A.P. Craig, W.G. Strand Jr., J.M. Arblaster, V.B. Wayland, R. James and Y. Zhang, 2000: Parallel Climate Model (PCM) control and transient simulations. Clim. Dyn., 16, 755-774.

Xie, P. and P.A. Arkin, 1996: Analyses of global monthly precipitation using gauge observations, satellite estimates, and numerical model predictions. J. Climate, 9, 840-858.

$\longrightarrow$ and $\longrightarrow$ 1997: Global precipitation: A 17year monthly analysis based on gauge observations, satellite estimates, and numerical model outputs. Bull. Amer. Meteor. Soc., 78, 25392558.

Yun, W.-T. and W.-T. Kwon, 2003: SVD multi-model superensemble technique for long-term prediction. Kor. J. Atmos. Sci., 5, 217-228.

- L. Stefanova and T.N. Krishnamurti, 2003: Improvement of the multimodel superensemble technique for seasonal forecasts. J. Climate, 16, 3834-3840.

Zhang, G.J. and N.A. McFarlane, 1995: Sensitivity of climate simulations to the parameterization of cumulus convection in the Canadian Climate Centre general circulation model. Atmos.Ocean, 33, 407-446. 